published in in D. Millimet, J. Smith, and E. Vytlacil (eds.),

Advances in Econometrics, Volume 21,

Modelling and Evaluating Treatment Effects in Econometrics, 2008, 289-333

\title{
MATCHING ESTIMATION OF DYNAMIC TREATMENT MODELS: SOME PRACTICAL ISSUES
}

\author{
Michael Lechner \\ SIAW \\ Swiss Institute for International Economics \\ and Applied Economic Research \\ University of St.Gallen
}

First version: January 2006

Revised: August 2008

Date this version has been printed: 03 August 2007

\begin{abstract}
Lechner and Miquel (2001) approached the causal analysis of sequences of interventions from a potential outcome perspective based on selection on-observables-type assumptions (sequential conditional independence assumptions). Lechner (2004) proposed matching estimators for this framework. However, many practical issues that might have substantial consequences for the interpretation of the results have not been thoroughly investigated so far. This paper discusses some of these practical issues. The discussion is related to estimates based on an artificial data set for which the true values of the parameters are known and that shares many features of data that could be used for an empirical dynamic matching analysis.
\end{abstract}

Keywords: Dynamic treatment regimes, nonparametric identification, causal effects, sequential randomization, program evaluation, treatment effects, dynamic matching, panel data.

JEL classification: C31, C41

\section{Address for correspondence}

Michael Lechner

University of St. Gallen, Swiss Institute for International Economics and Applied Economic Research (SIAW)

Bodanstr. 8, CH-9000 St. Gallen, Switzerland,

Michael.Lechner@unisg.ch,www.siaw.unisg.ch/lechner 


\section{Introduction*}

This paper addresses practical issues associated with the non- or semiparametric estimation of dynamic treatment models that are identified by sequential selection-on-observables (or conditional independence) assumptions.

While the effects of dynamic selection bias and the impact of sequential interventions have received little attention in the applied econometrics literature so far, there is a substantial literature about the estimation of average 'causal effects' of interventions using large micro data sets based on a static causal model. Angrist and Krueger (1999) and Heckman, LaLonde, and Smith (1999) provide comprehensive overviews of this vast literature. Several authors have addressed dynamic causal issues by using ad-hoc modifications of the static causal framework. For example, Bergemann, Fitzenberger, and Speckesser (2004) evaluate training program sequences, and Lechner (1999) and Sianesi (2004) propose procedures to deal with participants entering labor market programs at different points in their unemployment spell. In a related setting, Crépon and Kramarz (2002) use different 'start times' to analyze the effects of the introduction of a policy to reduce standard working hours in France. A similar problem is the issue of program duration as analyzed by Behrman, Sengupta, and Todd $(2004,2005)$ in the context of a school subsidy experiment. Because these papers use static models of potential outcomes, it is

\footnotetext{
* I have further affiliations with CEPR, London, ZEW, Mannheim, IZA, Bonn, and PSI, London. This paper benefited considerably from previous work with Ruth Miquel about sequential treatment models, as well as from the consistency checks she performed with the artificial data. I thank Conny Wunsch for careful proofreading of a previous version of this paper. Furthermore, I thank Jeff Smith and two anonymous referees for very helpful comments and suggestions. I revised this paper while visiting the University of Michigan. The hospitality of the Department of Economics at UM is appreciated.
} 
difficult to define the desired causal effect in such a way such that the impact of the (implicit) assumptions about the dynamic selection process on the estimand becomes apparent. ${ }^{1}$

Robins (1986) first suggested an explicitly dynamic causal framework based on potential outcomes that allows the definition of causal effects of dynamic interventions and systematically addresses this type of selection problem. His approach was subsequently applied in epidemiology and biostatistics (e.g. Robins, 1989, 1997, 1999, Robins, Greenland, and Hu, 1999, for discrete treatments; Gill and Robins, 2001 for continuous treatments) to define the effect of treatments in discrete time. Identification is achieved by sequential randomization assumptions (see the very comprehensible summary by Abbring, 2003). The effects are typically estimated using parametric models. Based on this framework, Murphy (2003) proposes estimators for optimal treatment rules that specify how the treatment changes over time depending on how covariates change.

Recently, Lechner and Miquel (2001, LM01 from now on) extend Robins’ (1986) framework to comparisons of more general sequences, to different parameters and selection processes, and to identifying assumptions that are more relevant in typical microeconometric studies. Focusing on the case when all elements that influence selection and outcomes at each stage of the sequence are observable, LM01 discuss different identification conditions required for particular dynamic

1 There are further connections to other strands of econometrics: For example, the literature on dynamic panel data models identified by sequential moment conditions (e.g. Chamberlain, 1987, 1992) and this approach are related. Another connection is with the literature on social learning. In particular, Manski (2004) is concerned with dynamic selection problems from one cohort to the next. However, he assumes that the outcome distribution is stationary over time, which is in sharp contrast to our modelling of the outcomes. Therefore, in his framework, as time goes by more information is revealed about the same counterfactual outcome distribution and social learning can be regarded as a process of reducing ambiguity resulting from the selection process. In the framework by LM01 used here, stationarity is not required and the uncertainty does not necessarily decrease over time. Finally, the work by Abbring and van den Berg (2003) addresses dynamic issues by using variation in the start time of treatment spells to identify the effects within a duration framework. Abbring and Heckman (2008) provide an overview of the different dynamic approaches. 
causal effects. Since the assumptions used in LM01 bear some similarity to the selection on observables or conditional independence assumption (CIA) that is prominent in the static evaluation literature, Lechner (2004, L04 from now on) proposed matching and inverse probability weighting estimators that are dynamic extensions of similar estimators used in the static model. These estimators retain most of the flexibility and convenience of the static methods that have made them the workhorse in empirical evaluation studies, particularly in Europe (see the excellent survey by Imbens, 2004, or Heckman, LaLonde, and Smith, 1999). Applications of the explicit dynamic causal framework based on potential outcomes are very rare in econometrics so far. $^{2}$

Since there are few experiences so far with this type of estimation for these models, this paper discusses several issues that come up when the dynamic approach is applied in practice. To begin with, three examples are chosen to show that the dynamic model can be fruitfully used to address questions that surface in applied evaluation studies and that are hard to address within a static framework, because the latter is not able to handle selection problems that occur while a particular treatment is in operation.

The first example concerns the effects of sequences of programs. The breakdown of the static model occurs when selection into the second and any subsequent programs is influenced by the outcome of the previous programs, so that particular control variables become endogenous in particular ways with respect to the complete sequence. The static model provides no way to handle such intermediate outcomes.

2 An exception is Ding and Lehrer (2003) who use this framework and related work by Miquel (2002, 2003) to evaluate a sequentially randomized class size study using difference-in-difference-type estimation methods. 
The second example concerns the effects of earlier or later program starts. As mentioned above, there have been attempts to estimate such effects in the evaluation literature by Sianesi (2004). ${ }^{3}$ However, her adjusted static framework does not clearly spell out the causal contrasts being estimated and does not explicitly define the exogeneity conditions required for the control variables to identify the underlying causal effect. The latter deficiency is shared by papers that try to mitigate the problem of different starting dates in evaluation studies by randomly drawing start dates (see Lechner, 1999, Gerfin and Lechner, 2002, and the critique of this procedure by Fredriksson and Johansson, 2003).

The third example is the effect of the actual duration of a program. The problem with the actual duration of a program is that it could be endogenous: For example, if the effect of a program comes from the signal that participation sends, then it is very likely that people will leave the program while it is under way. This attrition is, however, an effect of beginning and staying up to that point in the program. So far, empirical evaluation studies have circumvented this problem by considering the effects of planned duration only (e.g. Lechner, Miquel, and Wunsch, 2004). Such studies estimate a different parameter that may or may not be of interest in the particular situation.

The conditional independence assumption that justifies matching estimation in the static context is sometimes called a data hungry identification and estimation strategy. If static matching is data hungry, then dynamic matching is starving for data. This starvation relates to the number of observations necessary in the particular sequences to obtain precise inference, to the time-varying variables required to obtain identification, and to the heterogeneity of the characteristics observed in the particular treatments that may lead to support and over-parametrization problems. Taken together, these factors could lead to the undesirable situation that the price to pay for using the

3 See also the related approaches by Li, Propert, and Rosenbaum (2001) that appeared in the statistics literature. 
much more informative dynamic approach is that it produces very noisy estimates on a common support that has no policy relevance. Therefore, this paper considers these issues in greater depth from several different perspectives: (i) a comparison to static matching; (ii) the relation between the common support and the length of the specified sequences; (iii) the number of regressors included in the propensity score estimation.

This paper does not derive new analytical results. The discussion is based on known properties of the estimators, as well as on the performance of the estimation procedures in the data. These data come from a rather elaborate attempt to generate artificial data similar to that available in actual evaluation studies of European-type active labor market programs (many covariates, 40 periods with autocorrelation, four programs with different start dates and lock-in effects, etc.). Since in terms of computing time its generation is far too expensive for a Monte Carlo study, only one replication is used. For the limited illustrative goals of this paper, this suffices.

The paper proceeds as follows: Section 2 outlines the dynamic causal framework suggested by LM01 and L04. The notation is introduced and the basic identification conditions are restated. The estimation problem is explained in Section 3 and sequential matching as proposed by L04 is reviewed. Section 4 details the artificial data. Section 5 presents the three empirical examples. Section 6 covers the brief comparison to static matching. The issues of additional variables and the relation between length of sequence and common support are discussed in Section 7. Section 8 concludes and Appendix A contains some descriptive statistics concerning the distribution of the true values of the potential outcomes. 


\section{The dynamic causal model - notation, effects, and identification}

This section briefly repeats the definition of the dynamic causal model as well as the identification results derived by Lechner and Miquel (2001) for the case of sequential selection on observables. To ease the notational burden, I use a three-period-two-treatments model to discuss the most relevant issues that distinguish the dynamic from the static model, although in the application more periods and more treatments are considered. As usual in the econometric evaluation literature, I use the standard statistics terminology based on treatments and potential outcomes to define causal effects.

\subsection{Basic structure of the model}

Suppose that there is an initial period in which everybody is in the same treatment, plus two subsequent periods in which different treatment states are realized. The periods are indexed by $t$ or $\tau$ ( $t, \tau \in\{0,1,2\})$. The treatment defined over all periods is described by a vector of Bernoulli random variables $(\mathrm{RV}), S=\left(S_{1}, S_{2}\right)$. For notational convenience, the treatment of the initial period $\left(S_{0}=0\right.$ ) is not always mentioned explicitly. A particular realization of $S_{t}$ is denoted by $S_{t} \in\{0,1\}$. Denote the history of variables up to and including period $t$ by a bar below that variable, i.e. $\underline{s}_{2}=\left(s_{1}, s_{2}\right) .{ }^{5}$ Since we are not restricting effect heterogeneity over time, it makes sense to define potential outcomes in terms of sequences of potential states of the world. Thus, in period one, an individual (or a firm, country, or any other unit of interest) is observed in exactly one of two treatments. In period two, the same treatment occurring in that period will be captured by two different potential outcomes depending on what happened in period one. Therefore, an

\footnotetext{
5 To differentiate between different sequences, sometimes a letter (e.g. $j$ ) is used to index a sequence, as in $\underline{S}_{f}^{j}$. As a further convention, capital letters usually denote random variables, whereas small letters denote specific values of a random variable. When we deviate from this convention, the intended meaning will be obvious.
} 
individual participates in one of four treatments, defined by the sequences $(0,0),(1,0),(0,1)$, and $(1,1)$. Thus, every individual participates in exactly one sequence defined by $s_{1}$ and another sequence defined by the same value $s_{1}$ and a value of $S_{2}$. To sum up, in the two (plus one)-periodtwo-treatments example we consider six different overlapping potential outcomes corresponding to two mutually exclusive states defined by treatment status in period 1 only, plus four mutually exclusive states defined by treatment status in periods 1 and 2 together.

Variables used to measure the effects of the treatment in period $t$, i.e. the potential outcomes, are indexed by treatments and denoted by $Y_{t}^{s_{1}}(t \geq 1)$ or $Y_{t}^{s_{2}}(t \geq 2)$. They are measured at the end of each period, whereas treatment status is measured in the beginning of each period. For each sequence length ( 1 or 2 periods), one of the potential outcomes is observable and denoted by $Y_{t}$. The resulting observation rules are defined in equation (1):

$$
\begin{aligned}
& Y_{1}=S_{1} Y_{1}^{1}+\left(1-S_{1}\right) Y_{1}^{0} \\
& Y_{2}=S_{1} Y_{2}^{1}+\left(1-S_{1}\right) Y_{2}^{0}=S_{1} S_{2} Y_{2}^{11}+\left(1-S_{1}\right) S_{2} Y_{2}^{01}+S_{1}\left(1-S_{2}\right) Y_{2}^{10}+\left(1-S_{1}\right)\left(1-S_{2}\right) Y_{2}^{00} .
\end{aligned}
$$

Finally, variables that may influence treatment selection and (or) potential outcomes are denoted by $\boldsymbol{X}$. The $K$-dimensional vector $X_{t}$ may contain functions of $Y_{t}$ and is observable at the same time as $Y_{t}$.

\subsection{Average causal effects}

As in the static model, the potential outcomes are used to define several average causal effects. Equation (2) defines the causal effect (for period $t$ ) of a sequence of treatments up to period 1 or 2 $\left(\tau, \tau^{\prime}\right)$ compared to an alternative sequence of the same or a different length for a population defined by one of those sequences or a third sequence: 


$$
\begin{aligned}
& \theta_{t}^{\underline{s}_{t}^{k}, \underline{s}_{\tau}^{l}}\left(\underline{s}_{\tilde{\tau}}^{j}\right)=E\left(Y_{t}^{\underline{s}_{t}^{k}} \mid \underline{S}_{\tilde{\tau}}=\underline{s}_{\tilde{\tau}}^{j}\right)-E\left(Y_{t}^{\underline{s}_{s^{\prime}}^{l}} \mid \underline{S}_{\tilde{\tau}}=\underline{\underline{s}}_{\tilde{\tau}}^{j}\right), \\
& 0 \leq \tilde{\tau} ; \quad 1 \leq \tau, \tau^{\prime} \leq 2, \quad \tilde{\tau} \leq \tau^{\prime}, \tau ; \quad k \neq l, k \in\left(1, \ldots, 2^{\tau}\right), l \in\left(1, \ldots, 2^{\tau^{\prime}}\right), j \in\left(1, \ldots, 2^{\tilde{\tau}}\right)
\end{aligned}
$$

The treatment sequences indexed by $k, l$, and $j$ may correspond to (0) or (1) if $\tau$ (or $\tau^{\prime}$ ) denotes period 1 , or to the longer sequences $(0,0),(0,1),(1,0)$, or $(1,1)$ if $\tau$ (or $\left.\tau^{\prime}\right)$ equals two. LM01 call $\theta_{t}^{s_{t}^{k}, s_{s^{\prime}}^{s^{\prime}}}$ the dynamic average treatment effect (DATE). Accordingly, $\theta_{t}^{s_{t}^{k}, \underline{s}_{s^{\prime}}^{l}}\left(\underline{s}_{\tau}^{k}\right)$, as well as $\theta_{t}^{s_{t}^{k}, s_{r^{\prime}}^{l}}\left(\underline{s}_{s^{\prime}}^{l}\right)$ are termed DATE on the treated (DATET) and DATE on the nontreated. There are cases in between, like $\theta_{t}^{s_{2}^{k} ; s_{2}^{l}}\left(s_{1}^{l}\right)$, for which the conditioning set is defined by a sequence shorter than the ones defining the causal contrast. Note that the effects are symmetric for the same population $\left(\theta_{t}^{s_{t}^{k}, \underline{s}_{t}^{l}}\left(\underline{s}_{\tau}^{k}\right)=-\theta_{t}^{s_{t}^{l}, s_{t}^{k}}\left(\underline{s}_{\tau}^{k}\right)\right)$. This feature, however, does not restrict effect heterogeneity across individuals $\left(\theta_{t}^{\underline{s}_{*}^{k}, \underline{s}_{-}^{l}}\left(\underline{s}_{\tau}^{k}\right) \neq \theta_{t}^{\underline{s}_{t}^{k}}, \underline{s}_{-}^{l} \cdot\left(\underline{s}_{\tau^{\prime}}^{l}\right)\right)$.

\subsection{Identification}

Assume that a large sample $\left\{s_{1 i}, s_{2 i}, x_{0 i}, x_{1 i}, x_{2 i}, y_{1 i}, y_{2 i}\right\}_{i=1: N}$ of size $N$ is available, randomly drawn from a very large population of interest. The latter is characterized by the corresponding random variables $\left(S_{1}, S_{2}, X_{0}, X_{1}, X_{2}, Y_{1}, Y_{2}\right) \cdot{ }^{6}$ Furthermore, assume that all conditional expectations that are of interest in the remainder of this paper exist. To ease notation further, from now on assume that interest centers on the effects of sequences of length two only (effects of sequences of length one are not interesting, because their identification is discussed in the extensive static literature). LM01 show that if we can observe the variables that jointly influence selection at each stage as

6 To simplify the notation further, we consider period 2 as the only period relevant for the outcome of interest. However, for all that follows $X_{2}$ and $Y_{2}$ should be considered as measured at some point in time after treatment 2 
well as the outcomes some average treatment effects are identified by weak conditional independence assumptions: ${ }^{7}$

Weak dynamic conditional independence assumption $(W-D C I A)^{8}$

a) $\quad Y_{2}^{00}, Y_{2}^{10}, Y_{2}^{01}, Y_{2}^{11} \amalg S_{1} \mid X_{0}=x_{0}$;

b) $\quad Y_{2}^{00}, Y_{2}^{10}, Y_{2}^{01}, Y_{2}^{11} \amalg S_{2} \mid \underline{X}_{1}=\underline{x}_{1}, S_{1}=s_{1}$;

c) $1>P\left(S_{1}=1 \mid X_{0}=x_{0}\right)>0,1>P\left(S_{2}=1 \mid \underline{X}_{1}=\underline{x}_{1}, S_{1}=s_{1}\right)>0 ; \forall \underline{x_{1}} \in \underline{\chi}_{1}, \forall s_{1}: s_{1} \in\{0,1\}$.

$\underline{\chi}_{1}=\left(\chi_{0}, \chi_{1}\right)$ denotes the support of $X_{0}$ and $X_{1}$. Part a) of W-DCIA states that the potential outcomes are independent of treatment choice in period $1\left(S_{1}\right)$ conditional on $X_{0}$. This is the standard version of the static CIA (e.g. Rubin, 1974). Part b) states that conditional on the treatment in period 1 , on observable outcomes in period 1 (which may be part of $X_{1}$ ) and on the confounding variables from periods 0 and $1\left(\underline{X}_{1}\right)$, potential outcomes are independent of treatment choice in period $2\left(S_{2}\right)$.

To see whether such an assumption is plausible in a particular application, we have to ask which variables influence potential changes in treatment status as well as outcomes and whether they are observable. If the answer to the latter question is yes, and if there is common support (defined in part c) of W-DCIA), then we have identification, even if some or all of the conditioning variables in period 2 are influenced by the outcome of the treatment in period 1. LM01 show that, for example, quantities like $E\left(Y_{2}^{11}\right), E\left(Y_{2}^{11} \mid S_{1}=0\right), E\left(Y_{2}^{11} \mid S_{1}=1\right)$, or $E\left[Y_{2}^{11} \mid \underline{S}_{2}=(1,0)\right]$ are

occurred. The exact timing is determined by the substantive interest of the researcher conducting the empirical study.

7 The following assumptions relate to identification of all treatment effects that could possibly be defined by the notation in Section 2. If the desired comparison involves fewer periods, the required changes are obvious. 
identified, but that $E\left[Y_{2}^{11} \mid \underline{S}_{2}=(0,0)\right]$ or $E\left[Y_{2}^{11} \mid \underline{S}_{2}=(0,1)\right]$ are not identified. Thus, $\theta_{2}^{s_{2}^{k} ; s_{2}^{l}}$, $\theta_{2}^{s_{2}^{k} ; s_{2}^{l}}\left(s_{1}^{j}\right)$ are identified $\forall s_{1}^{k}, s_{2}^{k}, s_{1}^{l}, s_{2}^{l}, s_{1}^{j}, s_{2}^{j} \in\{0,1\}$, but $\theta_{2}^{s_{2}^{k}, s_{2}^{l}}\left(\underline{s}_{2}^{j}\right)$ is not identified if $s_{1}^{l} \neq s_{1}^{k}$, or $s_{1}^{l} \neq s_{1}^{j}$, or $s_{1}^{k} \neq s_{1}^{j}$. This result states that pair-wise comparisons of all sequences are identified, but only for groups of individuals defined by their treatment status in periods 0 or 1 . The relevant distinction between the populations defined by treatment states in the first and subsequent periods is that in the first period, treatment choice is random conditional on exogenous variables, which is the result of the initial condition stating that $S_{0}=0$ holds for everybody. However, in the second period, randomization into these treatments is conditional on variables already influenced by the first part of the treatment. W-DCIA has an appeal for applied work as a natural extension of the static framework. However, W-DCIA does not identify the classical treatment effects on the treated if the sequences of interest differ in the first period.

LM01 show that to identify all treatment parameters, W-DCIA must be strengthened by essentially imposing that the confounding variables used to control selection into the treatment of the second period are not influenced by the selection into the first-period treatment. This can be summerized by an independence condition like $Y_{2}^{s_{2}} \amalg \underline{S}_{2} \mid \underline{X}_{1}$ (LM01 call this the strong conditional dynamic independence assumption, $S$-DCIA). Note that the conditioning set includes the outcome variables from the first period. This is the usual conditional independence assumption used in the multiple treatment framework (with four treatments). In other words, when the control variables are not influenced by the previous treatments, the dynamic problem collapses to a static problem of four treatments with selection on observables.

$8 A \amalg B \mid C=c$ means that each element of the vector of random variables $B$ is independent of the random variable A conditional on the random variable $C$ taking a value of $c$ in the sense of Dawid (1979). 
It is a problem for any attempt at nonparametric estimation of these effects that adjustments based on a potentially high-dimensional vector of characteristics and intermediate outcomes $(X)$ are required (details below). Therefore, in the applied static matching literature balancing scores are a popular device to reduce the dimension of the estimation problem (see Rosenbaum and Rubin, 1983). LM01 show that similar properties hold for the dynamic model as well.

\section{Balancing score property for W-DCIA}

If the conditions of W-DCIA hold, then:

a) $\quad Y_{2}^{00}, Y_{2}^{10}, Y_{2}^{01}, Y_{2}^{11} \amalg S_{1} \mid b_{1}\left(X_{0}\right)=b_{1}\left(x_{0}\right)$ holds for all $b_{1}\left(x_{0}\right)$ such that

$$
E\left[p^{s_{1}}\left(x_{0}\right) \mid b_{1}\left(X_{0}\right)=b_{1}\left(x_{0}\right)\right]=p^{s_{1}}\left(x_{0}\right) ; \quad p^{s_{1}}\left(x_{0}\right):=P\left(S_{1}=s_{1} \mid X_{0}=x_{0}\right) .
$$

b) $\quad Y_{2}^{00}, Y_{2}^{10}, Y_{2}^{01}, Y_{2}^{11} \amalg S_{2} \mid b_{2}\left(\underline{X}_{1}, S_{1}\right)=b_{2}\left(\underline{x}_{1}, s_{1}\right)$ holds for all $b_{2}\left(\underline{x}_{1}, s_{1}\right)$ such that

$$
E\left[p^{s_{2} \mid s_{1}}\left(\underline{x_{1}}\right) \mid b_{2}\left(\underline{X}_{1}, S_{1}\right)=b_{2}\left(\underline{x}_{1}, s_{1}\right)\right]=p^{s_{2} \mid s_{1}}\left(\underline{x}_{1}\right) ; \quad p^{s_{2} \mid s_{1}}\left(\underline{x}_{1}\right):=P\left(S_{2}=s_{2} \mid \underline{X}_{1}=\underline{x}_{1}, S_{1}=s_{1}\right) .
$$

A low-dimensional choice for balancing scores suggested by LM01 consists of conditional transition probabilities in combination with the variable indicating the selection in the previous period (which of course can be ignored in the first period): $b_{1}\left(x_{0}\right)=p^{s_{1}}\left(x_{0}\right)$, $b_{2}\left(\underline{x}_{1}, s_{1}\right)=\left[p^{s_{2} \mid s_{1}}\left(\underline{x}_{1}\right), s_{1}\right]$.

\section{Estimation}

\subsection{Structure of sequential estimators}

Lechner (2004) shows that these scores are convenient for constructing sequential propensity score matching estimators to correct for selection bias under W-DCIA. I focus on this particular estimator because of its simplicity and because of its frequent use in empirical evaluation studies. Other static matching-type estimators can be adapted to the dynamic context in a similar way (see 
Imbens, 2004, for an overview of available estimators). I refrain from discussing estimation based on the S-DCIA explicitly, because estimation under S-DCIA is essentially a static problem with an increased number of treatments. Such estimation problems for multiple treatments are discussed by Imbens (2000) and Lechner (2001, 2002) and need not be explained here. Nevertheless, the suggested estimators are consistent under S-DCIA as well. Thus, a comparison of estimators that are consistent under both W-DCIA and S-DCIA (sequential matching) and those that are consistent under S-DCIA only (static matching) could serve as the basis for checking the plausibility of S-DCIA (or the endogeneity of some covariates). However, this point is not developed further in this paper.

Using the balancing scores suggested above the following estimand (quantity to be estimated by sample analogues of observables) results for quantities identified under W-DCIA:

$$
\begin{array}{r}
E\left(Y_{2}^{s_{2}^{k}} \mid S_{1}=s_{1}^{j}\right)=\underset{p^{s_{1}^{k}}\left(X_{0}\right)}{E}\left\{\underset{p^{s_{2} s_{1}^{k}}\left(\underline{X}_{1}\right)}{E}\left[E\left(Y_{2} \mid \underline{S}_{2}=\underline{s}_{2}^{k}, \underline{p}^{s_{2}^{k} \mid s_{1}^{k}, s_{1}^{k}}\left(\underline{X}_{1}\right)\right) \mid S_{1}=s_{1}^{k}, p^{s_{1}^{k}}\left(X_{0}\right)\right] \mid S_{1}=s_{1}^{j}\right\}, \\
\underline{p}^{s_{2}^{k} \mid s_{1}^{k}, s_{1}}\left(\underline{X}_{1}\right):=\left[p^{s_{2}^{k} \mid s_{1}^{k}}\left(\underline{X}_{1}\right), p^{s_{1}}\left(X_{0}\right)\right], \quad s_{1}^{k}, s_{2}^{k}, s_{1}^{j}, s_{1} \in\{0,1\} .
\end{array}
$$

To learn the counterfactual outcome for the population participating in $s_{1}^{j}$ (the target population) had they participated in sequence $\underline{s}_{2}^{k}$, we need to reweight the participants in $\underline{s}_{2}^{k}$ to make them comparable to the target population $\left(s_{1}^{j}\right)$. The dynamic, sequential structure of the causal model restricts the possible ways to do so. Intuitively, for the participants in the target population, we should reweight participants in the first element of the sequence of interest $\left(s_{1}^{k}\right)$ such that they have the same distribution of $p^{s_{1}^{k}}\left(X_{0}\right)$ as the target distribution. Call this artificially created group comparison group 1 . Yet, to estimate the effect of the full sequence, the outcomes of par- 
ticipants in $\underline{s}_{2}^{k}$ instead of $s_{1}^{k}$ are required. Thus, an artificial subpopulation of participants in $\underline{s}_{2}^{k}$ that has the same joint distribution of $p^{s_{1}^{k}}\left(X_{0}\right)$ and $p^{s_{2}^{k} s_{1}^{k}}\left(\underline{X}_{1}\right)$ as the artificially created comparison group 1 is required. The same principle applies for dynamic average treatment effects in the population (DATE).

All proposed estimators in L04 have the same structure, in the sense that they are computed as weighted means of the outcome variables observed in subsample $\underline{S}_{2}=\underline{s}_{2}^{k}$. The weights depend on the specific effects of interest and are functions of the balancing scores.

$$
\begin{aligned}
& \overline{E\left(Y_{2}^{s_{2}^{k}} \mid S_{1}=s_{1}^{j}\right)}=\sum_{i \in \underline{s}_{2}^{k}} w_{i}^{s_{2}^{k}, s_{1}^{j}}\left[\underline{p}^{s_{2}^{k} \mid s_{1}^{k}, s_{1}^{k}}\left(\underline{x_{1, i}}\right), s_{1}^{k}\right] y_{i} ; \quad w_{i}^{s_{2}^{k}, s_{1}^{j}} \geq 0 ; \quad \sum_{i \in \underline{s}_{2}^{k}} w_{i}^{s_{2}^{k}, s_{1}^{j}}=1 ; \\
& \left.\widehat{E\left(Y_{2}^{s_{2}^{k}}\right.}\right)=\sum_{i \in \underline{s}_{2}^{k}} w_{i}^{s_{2}^{k}}\left[\underline{p}^{s_{2}^{k} \mid s_{1}^{k}, s_{1}^{k}}\left(\underline{x}_{1, i}\right), s_{1}^{k}\right] y_{i} ; \quad w_{i}^{s_{2}^{k}} \geq 0 ; \quad \sum_{i \in \underline{s}_{2}^{k}} w_{i}^{s_{2}^{k}}=1 .
\end{aligned}
$$

Note that in the case of more than two treatments, the balancing scores for (4) and (5) will differ with respect to the probability of participating in the first period. For equation (4), the required quantity is $P\left(S_{1}=s_{1}^{k} \mid X_{0}=x_{0}, S_{1} \in\left\{s_{1}^{k}, s_{1}^{l}\right\}\right)$, whereas in equation (5), in which all of the population is the target, $P\left(S_{1}=s_{1}^{k} \mid X_{0}=x_{0}\right)$ is appropriate.

\subsection{Sequential matching estimators (SM)}

LM01 proposes to extend the simple pair-matching estimators that are highly popular in applied evaluation studies to the dynamic context. The idea is to perform the required adjustments by sequentially choosing close pairs of observations in the various steps, so as to mimic the sequential conditional expectations appearing in expressions (4) and (5). The first step is the same for both effects and consists in finding for every member of $S_{1}=s_{1}^{k}$ a member of $\underline{S}_{2}=\underline{s}_{2}^{k}$ with very 
similar (the same) values of $p^{s_{2}^{k} \mid s_{1}^{k}}\left(\underline{x}_{1, i}\right)$ and $p^{s_{1}^{k}}\left(x_{0, i}\right)$. Note that matching must be with replacement, because the target population may be larger than the treatment population. In the second step, every member of $S_{1}=s_{1}^{j}$ (equation (4)) or $S_{0}=0$ (equation (5)) is to be paired with a member of $S_{1}=s_{1}^{k}$ with very similar (same) values of $p^{s_{1}^{k}}\left(x_{0, i}\right)$. The positive weights that are attached to some or all members of $\underline{S}_{2}=\underline{s}_{2}^{k}$ coming from step 1 are then updated depending on how often an observation in $\underline{S}_{2}=\underline{s}_{2}^{k}$ is matched to an observation of the target population via the intermediate matching step. This procedure leads to the following weights:

$$
\begin{aligned}
& w_{i}^{s_{2}^{k}, s_{1}^{j}}=\frac{1}{N^{s_{1}^{j}}} \sum_{n \in s_{1}^{j}} \sum_{m \in s_{1}^{k}} v_{1}\left[p^{s_{1}^{k}}\left(x_{0, n}\right), p^{s_{1}^{k}}\left(x_{0, m}\right) ; \cdot\right] v_{2}\left[\underline{p}^{s_{2}^{k} \mid s_{1}^{k}, s_{1}^{k}}\left(\underline{x}_{1, m}\right), \underline{p}^{s_{2}^{k} \mid s_{1}^{k}, s_{1}^{k}}\left(\underline{x}_{1, i}\right), s_{1}^{k} ; \cdot\right] ; \forall i \in \underline{S}_{2}=\underline{s}_{2}^{k} ; \\
& w_{i}^{s_{2}^{k}}=\frac{1}{N} \sum_{n=1}^{N} \sum_{m \in s_{1}^{k}} v_{1}\left[p^{s_{1}^{k}}\left(x_{0, n}\right), p^{s_{1}^{k}}\left(x_{0, m}\right) ; \cdot\right] v_{2}\left[\underline{p}^{s_{2}^{k}||_{1}^{k}, s_{1}^{k}}\left(\underline{x}_{1, m}\right), \underline{p}^{s_{2}^{k} \mid s_{1}^{k}, s_{1}^{k}}\left(\underline{x}_{1, i}\right), s_{1}^{k} ; \cdot\right] ; \quad \forall i \in \underline{S}_{2}=\underline{s}_{2}^{k} .
\end{aligned}
$$

$N^{s_{1}^{j}}$ denotes the number of observations for which $S_{1}=s_{1}^{j}$. The function $v_{1}\left[p^{s_{1}^{k}}\left(x_{0, n}\right), p^{s_{1}^{k}}\left(x_{0, m}\right) ; \cdot\right]$ is defined to be one if $p^{s_{1}^{k}}\left(x_{0, m}\right)$ is closest to $p^{s_{1}^{k}}\left(x_{0, n}\right)$ among all observations belonging to the subsample defined by $S_{1}=s_{1}^{k}$, and zero otherwise. Similarly, $v_{2}\left[\underline{p}^{s_{2}^{k} \mid s_{1}^{k}, s_{1}^{k}}\left(\underline{x}_{1, m}\right), \underline{p}^{s_{2}^{k} \mid s_{1}^{k}, s_{1}^{k}}\left(\underline{x}_{1, i}\right), s_{1}^{k} ; \cdot\right]$ is one if observation $i$ is closest to observation $m$ (with $s_{1, m}=s_{1}^{k}$ ) in terms of $p^{s_{2}^{k} \mid s_{1}^{k}}\left(\underline{x}_{1, i}\right)$ and $p^{s_{1}^{k}}\left(x_{0, i}\right)$, and zero otherwise. The Mahalanobis metric (a quadratic form of the variables defining the distance weighted by the inverse of their sample covariance matrix) is a frequently used measure for similarity. Note that the weight of observation $i$ is 0 if it is not matched to any member of the target population. On the other extreme, if observation $i$ is matched to every 
member of the target population its weight would be 1 . A specific variant of this estimator is shown in Table 1 for the example of estimating $\theta_{t}^{s_{2}^{1}, s_{2}^{0}}\left(s_{1}^{1}\right)$.

Some remarks about this protocol that are already contained in L04 are worth repeating: First, matching is with replacement. Every step of the matching sequence is essentially the same as for matching in a static framework. However, sequential propensity score matching involves several probabilities in the second period matching step. Second, some issues arise from the sequential nature of matching. By choosing observations as matches with similar values of the probabilities instead of the same values (because such observations may not be available), it may happen that the probabilities attached to observations in early matching steps (relating to transitions in early periods) change over different sequential matching steps due to imprecise matching. To prevent this from happening, every matched comparison observation in period 2 is recorded with the values $\hat{p}_{i}^{s_{1}^{l}}$ of the observation it was matched to in period 1 , instead of its own ( $\hat{p}$ denotes a consistent estimate of $p$ ). Hence, the 'history' of the match, or, in other words, the characteristics of the reference distribution, does not change when the next match occurs in the subsequent period.

Third, to compute $E\left(Y^{s_{2}^{k}} \mid S_{1}=s_{1}^{l}\right)$ the only information that is needed for the $N^{s_{1}^{l}}$ participants in $s_{1}^{l}$ is $\hat{p}_{i}^{s_{1}^{k}}$. Similarly, for participants in $\underline{s}_{2}^{k}$, all probabilities of the type $\underline{\hat{p}}_{i}^{s^{k} \mid s_{1}^{k}, s_{1}^{k}}$ are required. For participants in $s_{1}^{k}$ but not in $\underline{s}_{2}^{k}$ only $\hat{p}_{i}^{s_{1}^{k}}$ is needed, and so on. To estimate $E\left(Y^{\underline{s}_{2}^{l}} \mid S_{1}=s_{1}^{l}\right)$ instead of $E\left(Y^{s_{2}^{k}} \mid S_{1}=s_{1}^{l}\right)$, the only change in the matching protocol is that the initial matching step on $\hat{p}_{i}^{s_{1}^{1}}$ is redundant. When interest is in the average effect in the population $\left(E\left(Y^{s_{2}^{k}}\right)\right)$, then the whole population plays the role of the first reference group (instead of $s_{1}^{l}$ ). In this case, in the 
matching step based on $\hat{p}_{i}^{s_{1}^{k}}$, all participants in $s_{1}^{k}$ are matched to themselves. In addition selected participants in $s_{1}^{k}$ are matched to participants in the remaining treatments in the first period.

Table 1 about here

When matching is on the propensity score instead of directly on the confounding variables, there is the issue of selecting a probability model. It seems that so far even in the static model the literature has not addressed this thoroughly. However, the consensus seems to be that a flexibly specified (and extensively tested) parametric model is sufficiently rich and that the choice of the model does not really matter (see e.g. the Monte Carlo results by Zhao, 2004). Similarly, the suggestions in the literature to guide the specification choice by the ability to achieve balance of the respective covariates (e.g. Rosenbaum and Rubin, 1994, or Rubin, 2004) can be applied here as well (in each step).

Next, there is the issue of consistent estimation of the standard errors that is not yet resolved for the static matching literature. Based on the simulation results presented in L04, the standard errors are computed conditional on the weights. In other words, the fact that the weights are estimated quantities is ignored. Furthermore, the outcomes may be conditionally heteroscedastic. However, heteroscedasticity is only relevant in this context if related to the weights. Therefore, a simple k-nearest neighbor estimator is used as in L04 to adjust for any such heteroscedasticity. Although such an estimator performed well in L04, there is potential for improvement.

The final remark about the matching protocol concerns the common support. The region of common support - defined on the reference distribution for which the effect is desired - has to be ad- 
justed period by period with respect to the conditioning variables of that period. The matching estimator makes it easy to trace back the impact of this procedure on the reference distribution. ${ }^{9}$

\subsection{Multiple treatments and many periods}

The main issue concerns the specification of the propensity scores: For example, when specifying the probability of participating in $s_{2}^{k}$ conditional on participating in $s_{1}^{k}$, is it necessary to take account of the fact that not participating in $s_{2}^{k}$ implies a range of possible other states in period 2 ? The answer is no, because in each step the independence assumption relates only to a binary comparison, e.g. $\quad Y_{2}^{s_{2}^{k}} \amalg \underline{1}\left(S_{2}=s_{2}^{k}\right) \mid S_{1}=s_{1}^{k}, \underline{X}_{1}=\underline{x_{1}}$, and $Y_{2}^{s_{1}^{k}} \amalg \underline{1}\left(S_{1}=s_{1}^{k}\right) \mid S_{1} \in\left\{s_{1}^{j}, s_{1}^{k}\right\}, X_{0}=x_{0} \quad\left(s_{1}^{j}\right.$ being the target population as before). Therefore, the conditional probabilities of not participating in the event of interest conditional on the history are sufficient. ${ }^{10}$ Hence, as already noted $P\left(S_{2}=s_{2}^{k} \mid S_{1}=s_{1}^{k}, \underline{X}_{1}=\underline{x}_{1}\right)$ and $P\left(S_{1}=s_{1}^{k} \mid X_{0}=x_{0}, S_{1} \in\left\{s_{1}^{l}, s_{1}^{k}\right\}\right)$ may be used in the matching step in period 1 . The multiple treatment feature of the problem does not add to the dimension of the propensity scores.

\section{$4 \quad$ Data}

The artificial data are generated to look similar to individual panel data found in actual evaluation studies of European-type active labor market programs (such as Gerfin and Lechner, 2002, or Lechner, Miquel, and Wunsch, 2004), although the exact properties of those data sets used for static evaluation studies are not reflected in the artificial data. In these data, a period is

\footnotetext{
9 In the application the support is defined slightly more conservatively than given in Table 1 . It is the region between the second largest and second smallest value of the respective propensity scores in the reference distribution.

${ }^{10}$ Imbens (2000) and Lechner (2001) develop the same argument to show that in static multiple treatment models conditioning on appropriate one-dimensional scores is sufficient.
} 
rationalized as a quarter. In that sense, there is detailed information about many employment related variables on a quarterly basis for 9 years (quarter 1(1) to quarter 9(4)). In addition, there are summary measures that aim to capture the events before the data is recorded in quarterly intervals. ${ }^{11}$

The sample is selected to contain all 'individuals' who are unemployed in the last quarter of year 2, denoted as 2(4). Starting in the first quarter in year 3, individuals may participate in active labor market programs. If not having done so before, they may start a program every quarter up to and including 4(2). In addition, in 4(2) they may start a new program, even if they already participated in a program completed before 4(2).

There are two employment programs (treatments '3' and '4') and two training programs (treatments ' 1 ' and '2'). The main difference between the two types is that employment programs have a smaller lock-in effect and that the positive medium-run effects that all programs have deteriorate at a faster rate than for the training programs.

We consider (potential) outcome processes for all sequences of different programs that relate to employment status (employed, unemployed, out of the labor force) and earnings. All processes show considerable state dependence, embody time trends and are influenced by several covariates. Shorter programs with a mean of about 5 months for training and 6 months for the employment programs (standard deviation 2 and 4 months) have much shorter lock-in effects than the longer programs of the same category (mean duration 20, 18; std. dev.: 2, 4), but the (positive) effects also depreciate faster. However, for the sake of brevity the longer program types are not contained in the descriptive statistics given in Table 2.

\footnotetext{
11 Since space constraints do not allow reproducing the data generating process exactly, a Gauss 6.0 program is available from the author on request.
} 
Table 2 contains descriptive statistics as well as a characterization of the variable type for the most important time-dependent and time-independent variables in the specific subsamples defined by treatment status. They are the usual types of variables with typical codings, means, and standard errors. A full set of statistics for all variables is available on request from the author. Note that the treatment sequences that define the appropriate subsamples are abbreviated by strings that contain a treatment state for every period. For example, 222222 means six periods for treatment 2, whereas 01000 would mean one period of treatment 0 , followed by a period of treatment 1 , followed again by 4 periods of treatment 0 .

Table 2 about here

Selection is based on an index model (multinomial probit) with five alternatives. Choices depend on observables that also appear in the outcome processes as well as normally distributed unobservables that are mutually dependent but independent of the observables and unobservables appearing in the outcome equations. All selection processes fulfill W-DCIA. With the exception of nationality, all variables appearing in Table 2 influence selection in each period, but only earnings, the employment states, and the assessment by the case worker are influenced by the treatment and are thus considered outcome variables, or intermediate outcomes for those variables that relate to periods in which the sequences are not yet completed. Comparing the value of the covariates and intermediate outcomes across sequences reveals considerable selection effects as well as considerable differences in the moments of the outcome variables.

The actual probit models underlying the results presented in the following sections are misspecified, but in ways that remain largely undetected by conventional specification tests. The misspecification relates to the functional form (only single models instead of the underlying multiple index models are used) as well as to omission of some covariates that are highly correlated 
with covariates included in the sample. In this respect as well, the artificial data seem to exhibit the same problems and questions as real data sets usually do.

The effects of the programs are heterogeneous depending on the type and duration of program, as well as on several covariates. They show lock-in effects that depend on program duration. The effects of the programs all depreciate, but with different speeds. The autocorrelation in the outcome process may increase the lock-in effect and dampen the depreciation. Table A.1 in Appendix A, as well as Tables 6, 7 and 8, show means and standard deviations for some outcomes of selected sequences and subsamples.

\section{$5 \quad$ Interesting causal effects and estimation results}

The static model of potential outcomes may also be used to define potential states of the world for dynamic phenomena and to estimate the effects by the usual econometric methods. Using a static model, each possible sequence of treatments corresponds to one 'static' treatment. The limitation of the static models relates to how restrictions on the joint distribution of selection variables and potential outcome variables have to be formulated in order to identify some average causal effects. By the nature of the static model, those restrictions cannot take into account selection effects based on intermediate outcomes. For example, if a conditional independence (selection on observables) assumption is deemed plausible, then variables that are determined by the treatment (a particular type of 'endogenous' variables) should not appear in the conditioning set, thus ruling out intermediate outcomes. ${ }^{12}$ Thus, it would be straightforward to accommodate dynamic phenomena based on the strong dynamic conditional independence assumption (S-

\footnotetext{
12 See the papers by Frölich (2006), Rosenbaum (1984), and Lechner (2008) on the type of endogenous variables that can be allowed for in the static causal model under selection on observables and on the consequences if variables that exhibit other types of endogeneity are included.
} 
DCIA). This is not the case for the weak dynamic conditional independence assumption (WDCIA), which allows some specific forms of endogeneity of the covariates.

The following sub-sections give some examples (sequences of programs, waiting for the start of a program, and duration of a program) when such considerations appear to be particularly relevant, discuss potential ways of setting up the estimation problems and present some results. A nice byproduct of the dynamic approach compared to the static approach is that one has to be explicit about what the alternative treatment state is, i.e. whether we compare two periods of treatment to one period of no treatments, or two periods of no treatment, or any other treatment-by-period combination. In many empirical evaluation papers, the no-treatment state is not clearly defined.

\subsection{Program sequences}

Consider an example coming from the literature on evaluating training programs in which interest is not in the effect of one particular program, but of a sequence of programs. However, if the first course of such a sequence is very effective, many unemployed individuals may find that their employment chances have drastically increased afterwards and may not want to attend the next course as originally intended. If interest is not in the first course, but in the sequence of courses, such behavior creates a selection problem that cannot be addressed in the static model. For example, controlling for pre-training variables does not work for obvious reasons in the static model, because an important selection variable, i.e. the outcome of the first participation, is missing. However, controlling for variables realized after the first training course that influence selection into the second course entails the potential problem that they may be influenced by the first part of the training sequence. Thus, they are 'endogenous' in the static model and, therefore, ruled out as control variables. If it is true that selection in each period is based on what is known about the unemployed so far, and that this information is observed, then W-DCIA holds. 
Table 3 shows some comparisons of the (monthly) earnings effects of different sequences of programs (each sequence starts in period 3(1) and contains the treatment states for the following periods). To differentiate between short-run and medium- to long-run effects, the columns of Table 3 (as well as Tables 4 and 5) provide estimates for the periods 4(4), 7(4), and 9(4) for the different sequences under investigation. Whereas in period 4(4) some of the programs of interest may still be running, in period 9(4) the different lengths of the sequences and programs are not important anymore, because all potential outcomes are close to their long-run levels. The rows of these tables contain further information about the sample sizes of the target populations after imposing the common support condition, and on the two counterfactual mean outcomes and the resulting treatment effects. The cells that contain the latter are shaded. Estimated standard errors appear in parentheses below the corresponding estimates of outcomes and effects.

Table 3 about here

For the interpretation of the estimated effects and counterfactual outcomes, it is important to note that whenever the potential state ' 0 ' appears, it does not necessarily mean that the individual is unemployed, but merely that she is not participating in some program in that period. The first practical problem that appears is that there are many possible comparisons. Here, we focus on different programs of a length of 3 periods that may or may not be followed by the start of a further program in period 4(2). The duration of the latter program is not part of the explicit definition of the effect. To capture the effects of having or not having a second program in period 4(2), all sequences have to be fully specified for at least 6 periods. Thus, a sequence like 111002 should be interpreted as participating in program 1 for three quarters and then starting program 2 in 4(2). The dynamic causal model allows the researcher to fix the duration of the first program, and thus isolate the effects of different program durations (see next section) from sequences of 
programs. Of course, the duration of the second program could be fixed as well, but that would lead to very small sample sizes in this example.

Table 3 shows a variety of potentially interesting comparisons for different target populations, namely those who participated in a program in the first period and the non-participants in that period. Since W-DCIA has only limited identifying power, the reference populations are based on the treatment status in the first period. Compared to nonparticipation, the results show lock-in effects of different sizes, and - with the exception of program 4 - considerable positive effects thereafter (although there is sometimes a lack of precision), a finding that is line with the true values that can be found in Appendix A. There is considerable effect heterogeneity across target populations. ${ }^{13}$ Furthermore, the estimates from the comparisons of the different programs to each other are too noisy to pin down any medium- to long-run effects in a precise way.

The precision of the estimates depends on the number of 'useful' observations (i.e. observations that are comparable to those in the target populations) in the sequences, which is of course related to the length of the specified sequence. The longer the sequence the more precise is the meaning of the causal contrast but the smaller the remaining number of observations available to estimate it. Furthermore, an increased number of observations in the target population increases precision as well, as the estimates that compare the same sequences for different target populations in Table 3 illustrate.

\footnotetext{
${ }^{13}$ Note that their effective sample sizes and composition after imposing common support depend on the sequences under investigation. Thus, computing the effects of 222001 compared to 222000 for participants in 2 by using the results of 222000 compared to 000000 for participants in 2 and 222001 compared to 000000 for participants in 2 is not strictly valid because those comparisons may be based on different common supports. The direct comparison of 222000 to 222001 could be based on yet another common support.
} 


\subsection{Delayed program start - the effects of waiting}

In the previous section, the specification of the target quantity for which the causal contrast is desired is relatively straightforward. In contrast, when interest lies in the effect of waiting for the start (or delaying the start) of a program, there are different ways to state the causal parameter. The first possibility is to just concentrate on the beginning of the program and to take no account of the fact that programs that may start at different points in time may also differ in other ways such as their duration. Such a comparison is displayed in the top panel of Table 4. Note that the required sequences have different lengths. It appears that for program 1 the long-run effects of delaying are small in this set-up, which is again in line with the true values.

The alternative (or the complement) to this approach is to require some minimum program duration, as is shown in the bottom panel for program 3. For that program the estimation results do not change much when different minimum lengths are considered. The price to pay for specifying longer sequences is of course a reduction in the precision of the estimator. Although program 3 is a longer program, there is not very much attrition in the first three periods considered in Table 4 (which is also the reason why the results do not change much when increasing the length of the sequences). Note that the comparisons of the different effects for the same target population are sometimes hampered by the fact that the common support may shrink drastically when the length of the sequence increases, because the participants tend to become more homogenous the longer the sequences. This issue is taken up again below.

Table 4 about here

Of course, many more interesting contrasts could be considered, such as requiring exactly the same length for both programs. However, they are beyond the illustrative nature and the space constraints of this paper. 


\subsection{The effects of the duration of a program}

In this section, I take up the issue of how to measure the effects of different program durations. The comparison of interest is the effect of an extension of a program. Table 5 shows the results for extensions of 1, 2, or 3 periods. The results differ according to whether the extensions concern only the minimum duration (upper panel) or the actual duration (lower panel). In the long run the estimates reflect positive effects of program duration, although, as observed before, precision becomes an issue when the specified sequence gets longer.

Table 5 about here

Note that the static evaluation literature typically refrains from estimating the effects of actual duration, because the programs themselves can cause attrition and thus actual duration cannot be used to differentiate between shorter and longer programs. As long as the relevant factors are observable, so that the W-DCIA holds, this issue is not a problem here and the effects can be estimated directly.

\section{A comparison to static matching}

Having discussed some of the questions that can be fruitfully addressed using the dynamic treatment approach, this section is concerned with a comparison of the sequential estimators and static approximations of the dynamic problem. For the latter, there are (at least) two possible implementations: The first one ignores the role of the intermediate outcomes as selection variables for the reason that they are endogenous relative to the beginning of the sequence. The second approximation includes those variables in the list of covariates.

There are two a priori reasons why static and dynamic matching estimators may deviate. First, the static version is biased if S-DCIA fails. Second, the estimates may be based on different populations because of different common supports. Different common supports become an issue 
particularly when the static approach does not use the intermediate outcomes. As the bias of the static estimator is extensively documented in L04, I refrain from searching for an example for which the bias is sufficiently substantial on the same common support. Instead, I employ the same example that will appear below when discussing the common support problem.

In Table 6 column (1) defines the relevant comparisons and the target population. Column (2) gives the sample sizes for the treatment groups as well as for the target populations after having imposed common support. The latter depends on the particular sequences under consideration. Column (3) shows the (unadjusted) sample means of the outcome variables in the various subpopulations. Comparing these sample means to the true mean values of the potential outcomes given in column (5) gives some indication of the selection bias that should be corrected for by matching. Columns (7) to (10) contain the results for the static matching, whereas columns (11) and (12) contain the corresponding results for sequential matching.

Table 6 about here

The first observation is that the results for static matching may differ substantially depending on whether the intermediate outcomes are included, or not. In the latter case, the results are typically closer to those of the dynamic matching, which in turn are not too far away from the true values (although due to the sampling uncertainty it is hard to pin down differences precisely with the sample sizes used). The second observation is that the common support issue does play a major role, as can be seen by the changing number of observations, by the sample means of the outcome variable for the target population as well as by the different estimates for the shortest sequence ' 1 ' that is not subject to the bias due to ignored dynamics. Since the common support issue resurfaces in almost every discussion of the results so far, it is discussed explicitly in the next section. 


\section{$7 \quad$ Some potential problems}

\subsection{Common support}

It has already been pointed out that the comparisons of the different effects for the same target population may be hampered by the fact that the common support may shrink drastically when the length of the sequences increases, because the participants tend to become more homogenous the longer the sequences.

Table 7, which is organized in the same way as Table 6, addresses this issue explicitly for two comparisons. First, the effect of waiting defined by explicitly increasing waiting time (and thus the length of the comparison sequence) from one period to five periods is considered. It appears that the sample size of the target population (participants in the one-period treatment) drops from 8800 to only 3400 for the sequence defined over 6 periods. Comparing the changing values of the true potential outcomes in the target populations before and after imposing common support shows that the populations are indeed very different. Whereas in the initial target population mean potential earnings for at least one period of program 1 was 4022 EUR, within the common support for the comparison of 1 to 000001 the mean potential outcome is less than half that value at 1590 EUR.

A similar picture arises in the bottom panel of Table 7, where different minimum durations of participation in program 2 are compared to spells of non-participation of the same minimum duration, although the drop is much less dramatic.

Table 7 about here

Again, these examples point out that there is a price to pay for getting a more precise definition of treatment and the selection effects within a nonparametric framework, because only relatively small parts of the sample may contain useful information for particular dynamic sequences. The 
problem of small sample size can be remedied in the three usual ways: The first option is to change the parameter of interest by specifying shorter sequences. This corresponds to aggregating over some longer sequences. The second option is to use parametric assumptions to add additional smoothness to the estimation problem. This is, however, not the subject of this paper. The third option is to collect more data.

Note that these findings are fairly robust to a more conservative definition of the common support, such as the region between the 10th largest / smallest value of the respective scores as opposed to the second largest / smallest value as in the baseline estimation.

\subsection{Too many covariates may be needed to control selection}

A potential drawback of the sequential matching approach is that the number of theoretically required covariates increases with the length of the sequence specified, because all the past intermediate outcomes observable at each node of a sequence should be included. When matching is on the propensity score, it implies that the dimension of the matching problem is increasing even if a parametric propensity score is used. The reason is that all past scores should be included as well. Furthermore, estimating a propensity score becomes more demanding when moving along the sequences, as the number of variables increases. Both potential problems could become more severe due to fact that the number of observations decreases when moving along the sequence. Finally, increasing the number of control variables could also potentially decrease the number of observations that remain in the target population that remain after imposing common support and thus change the estimand considerably.

Table 8 about here

Table 8 documents some of these problems by comparing two sequential matching estimators based on different specifications of the covariates applied to both a long and a short sequence. 
"All X" defines a specification in which all variables that are theoretically required are included (up to 28 for sequence 01 and up to 39 for 000001). ${ }^{14}$ "Few X" defines a specification that includes only the most recent information about the employment history and intermediate outcomes, leading to only 22 variables in both cases. ${ }^{15}$

When considering the results for employment rates and earnings, there appear to be no significant differences for the employment rates. For the longer sequences and their effect on earnings, the target populations change to some extent in this example (compare the true values of the target population adjusted for the common support given by the two different estimators). However, the results for both specifications are still close to the true values. The fact that both specifications are close is probably because the observed intermediate outcomes are highly correlated and including only the last one is (almost) sufficient. On the other hand, the specification with all variables included does not seem to be plagued by small sample problems due to potential overparametrization (indeed it seems to be preferable to the one that leaves out some variables), so that, in this example, it seems safe to include all of the variables in the specification that are required by theory.

\section{Conclusions}

This paper attempted to show that dynamic matching estimation can be a useful additional tool for empirical researchers because in many important cases it allows the researcher to define the

\footnotetext{
${ }^{14}$ For the longer sequence the intermediate outcomes of only every second period are included in the probits, because otherwise it would not converge for the last node in the sequence.

${ }^{15}$ For the comparison of 1 to 01 , the specification with fewer covariates captures the employment history before 2(4) only with variables from period $2(2)$ as well as with the usual time-constant variables, whereas the full specification uses a much richer set of covariates.
} 
causal parameter of interest more precisely and to address selection problems that occur while the treatment under consideration is in progress.

However, there is a price for getting a more precise definition of treatment and the selection effects within this nonparametric framework, because only relatively small parts of the sample may contain useful information for the particular dynamic sequences of interest (dynamic matching is an identification and estimation strategy starving for data). This problem of small sample sizes can be addressed by aggregating over some longer sequences. This however changes the parameter of interest and brings the dynamic model closer to the static one. Alternatively, one may consider parametric assumptions to add additional smoothness to the estimation problem. In the future, this option may be explored in more depth.

\section{Appendix A: Description of outcome heterogeneity}

Tables A.1 and A.2 contain some descriptive statistics for the true potential outcome variables that can be used to deduce the true effects. To avoid flooding the reader with numbers that are not helpful in interpreting the results that appear in the main body of the paper, we give means and standard deviations for earnings (A.1) and employment (A.2) only for sequences and subsamples that have some relation to the effects considered above.

Tables A.1a, A.1b, A.2a, A.2b about here

\section{References}

Abbring, J.H., 2003. Dynamic Econometric Program Evaluation. IZA, Discussion Paper, 804.

Abbring, J.H., Heckman, J.J., 2008. Dynamic Policy Analysis, mimeo. Dynamic policy analysis". Forthcoming as Chapter 24 in Matyas, L., Sevestre, P. (Eds.), The Econometrics of Panel Data (third edition), Kluwer, Dordrecht. Abbring, J.H., van den Berg, G., 2003. The Nonparametric Identification of Treatment Effects in Duration Models. Econometrica, 71, 1491--1517. 
Angrist, J. D., Krueger, A. B., 1999. Empirical Strategies in Labor Economics, in: Ashenfelter, O., Card D. (Eds.), Handbook of Labor Economics, Vol. III A, North-Holland, Amsterdam, 1277--1366.

Behrman, J., Sengupta, P., Todd, P., 2005. Progressing through PROGRESA: An Impact Assessment of a School Subsidy Experiment in Mexico. Economic Development and Cultural Change, 54 / 1, 237--275.

Behrman, J., Y. Cheng, Todd, P., 2004. Evaluating Preschool Programs when Length of Exposure to the Program Varies: A Nonparametric Approach. Review of Economics and Statistics, 86, 108--132.

Bergemann, A., Fitzenberger, B., Speckesser, S., 2004. Evaluating the Dynamic Employment Effects of Training Programs in East Germany using Conditional Difference-in-Differences. ZEW, Discussion Paper 04-41.

Chamberlain, G., 1987. Asymptotic Efficiency in Estimation with Conditional Moment Restrictions. Journal of Econometrics, 34, 305--334.

Chamberlain, G., 1992. Comment: Sequential Moment Restrictions in Panel Data. Journal of Business \& Economic Statistics, 10, 20--26.

Crépon, B., Kramarz, F., 2002. Employed 40 Hours or Not-Employed 39: Lessons from the 1982 Workweek Reduction in France. Journal of Political Economy, 110, 1355--1389.

Dawid, A. P., 1979. Conditional Independence in Statistical Theory. Journal of the Royal Statistical Society B, 41, 1$-31$.

Ding, W., Lehrer, S.F., 2003. Estimating Dynamic Treatment Effects from Project STAR, mimeo.

Fredriksson, P., Johansson, P., 2003. Program Evaluation and Random Program Starts, IFAU Discussion Paper, 2003(1), Uppsala.

Frölich, M., 2006. A Note on Parametric and Nonparametric Regression in the Presence of Endogenous Control Variables. Discussion Paper, Department of Economics, University of St. Gallen.

Gerfin, M., Lechner, M., 2002. Microeconometric Evaluation of the Active Labour Market Policy in Switzerland. The Economic Journal, 112, 854--893.

Gill, R. D., Robins, J. M., 2001. Causal Inference for Complex Longitudinal Data: The Continuous Case. The Annals of Statistics, 2001, 1--27. 
Heckman, J. J., LaLonde, R. J., Smith, J. A., 1999. The Economics and Econometrics of Active Labor Market Programs, in Ashenfelter, O., Card, D. (Eds.), Handbook of Labor Economics, Vol. III A, North-Holland, Amsterdam, 1865--2097.

Imbens, G. W., 2000. The Role of the Propensity Score in Estimating Dose-Response Functions. Biometrika, 87, 706--710.

Imbens, G. W., 2004. Nonparametric Estimation of Average Treatment Effects under Exogeneity: A Review. Review of Economics and Statistics, 86(1), 4--29.

Lechner, M., 1999. Earnings and Employment Effects of Continuous Off-the-job Training in East Germany after Unification. Journal of Business \& Economic Statistics, 17, 74--90.

Lechner, M., 2001. Identification and Estimation of Causal Effects of Multiple Treatments under the Conditional Independence Assumption, in Lechner, M., Pfeiffer, F. (Eds.), Econometric Evaluation of Active Labour Market Policies, Physica, Heidelberg, 43--58.

Lechner, M., 2002. Programme Heterogeneity and Propensity Score Matching: An Application to the Evaluation of Active Labour Market Policies. Review of Economics and Statistics, 84, 205--220.

Lechner, M., 2004. Sequential Matching Estimation of Dynamic Causal Models. University of St. Gallen, Discussion paper; revised 2005.

Lechner, M., 2008. A Note on Endogenous Control Variables in Causal Studies. Forthcoming in Statistics and Probability Letters.

Lechner, M., Miquel, R., 2001. A Potential Outcome Approach to Dynamic Programme Evaluation - Part I: Identification, Discussion paper 2001-07, Department of Economics, University of St. Gallen; revised 2005.

Lechner, M., Miquel, R., Wunsch, C., 2004. Long-run Effects of Public Sector Sponsored Training in West Germany", Discussion Paper 2004-19, Department of Economics, University of St. Gallen.

Li, Y. P., Propert, K. J., Rosenbaum, P., 2001. Balanced Risk Set Matching. Journal of the American Statistical Association, 96, 870--882.

Manski, C.F., 2004. Social Learning From Private Experiences: The Dynamics of the Selection Problem. Review of Economics Studies, 71, 443--558. 
Miquel, R., 2002. Identification of Dynamic Treatments Effects by Instrumental Variables. University of St. Gallen, Discussion paper, 2002-11.

Miquel, R., 2003. Identification of Effects of Dynamic Treatments with a Difference-in-Differences Approach. University of St. Gallen, Discussion paper, 2003-06.

Murphy, S.A., 2003. Optimal Dynamic Treatment Regimes. Journal of the Royal Statistical Society, Series B, 65, 331--366.

Robins, J. M., 1986. A New Approach to Causal Inference in Mortality Studies with Sustained Exposure Periods Application to Control of the Healthy Worker Survivor Effect. Mathematical Modelling, 7, 1393--1512, with 1987 Errata to: A New Approach to Causal Inference in Mortality Studies with Sustained Exposure Periods Application to Control of the Healthy Worker Survivor Effect. Computers and Mathematics with Applications, 14, 917--921; 1987 Addendum to: A New Approach to Causal Inference in Mortality Studies with Sustained Exposure periods - Application to Control of the Healthy Worker Survivor Effect. Computers and Mathematics with Applications, 14, 923--945; and 1987 Errata to: Addendum to 'A New Approach to Causal Inference in Mortality Studies with Sustained Exposure Periods - Application to Control of the Healthy Worker Survivor Effect'. Computers and Mathematics with Applications, 18, 477.

Robins, J.M., 1989. The Analysis of Randomized and Nonrandomized AIDS Treatment Trials Using a New Approach to Causal Inference in Longitudinal Studies, in Sechrest, L., Freeman, H., Mulley, A. (Eds.), Health Service Research Methodology: A Focus on Aids, 113-159, Washington, D.C., Public Health Service, National Centre for Health Services Research.

Robins, J.M., 1997. Causal Inference from Complex Longitudinal Data. Latent Variable Modelling and Applications to Causality, in Berkane, M. (Ed.), Lecture Notes in Statistics (120), Springer, New York, 69--117.

Robins, J. M., 1999. Association, Causation, and Marginal Structural Models. Synthese, 121, 151--179.

Robins, J.M., Greenland S., Hu, F., 1999a. Estimation of the Causal Effect of a Time-varying Exposure on the Marginal Mean of a Repeated Binary Outcome. Journal of the American Statistical Association, 94, 687--700.

Robins, J.M., Greenland, S., Hu, F., 1999b. Estimation of the Causal Effect of a Time-varying Exposure on the Marginal Mean of a Repeated Binary Outcome: Rejoinder. Journal of the American Statistical Association, 94, 708--712. 
Rosenbaum, P.R., 1984. The Consequences of Adjustment for a Concomitant Variable That Has Been Affected by the Treatment. Journal of the Royal Statistical Society, Series A, 147, 656--666.

Rosenbaum, P. R., Rubin, D. B., 1983. The Central Role of the Propensity Score in Observational Studies for Causal Effects. Biometrika, 70, 41--50.

Rosenbaum, P. R., Rubin, D. B., 1984: Reducing Bias in Observational Studies Using Subclassification on the Propensity Score. Journal of the American Statistical Association, 79, 516--524.

Rubin, D. B., 1974. Estimating Causal Effects of Treatments in Randomized and Nonrandomized Studies. Journal of Educational Psychology, 66, 688--701.

Rubin, D. B., 2004. On Principles for Modeling Propensity Scores in Medical Research. Pharmacoepidemiology and Drug Safety, 2004, 13, 855-857.

Sianesi, B., 2004. An Evaluation of the Swedish System of Active Labour Market Programmes in the 1990s. The Review of Economics and Statistics, 86, 133--155.

Zhao, Z., 2004. Using Matching to Estimate Treatment Effects: Data Requirements, Matching Metric and a Monte Carlo Study. The Review of Economics and Statistics, 86, 91--107. 


\section{Tables}

Table 1: A sequential matching estimator for $\theta_{t}^{s_{2}^{1}, s_{2}^{0}}\left(s_{1}^{1}\right)$ based on propensity scores

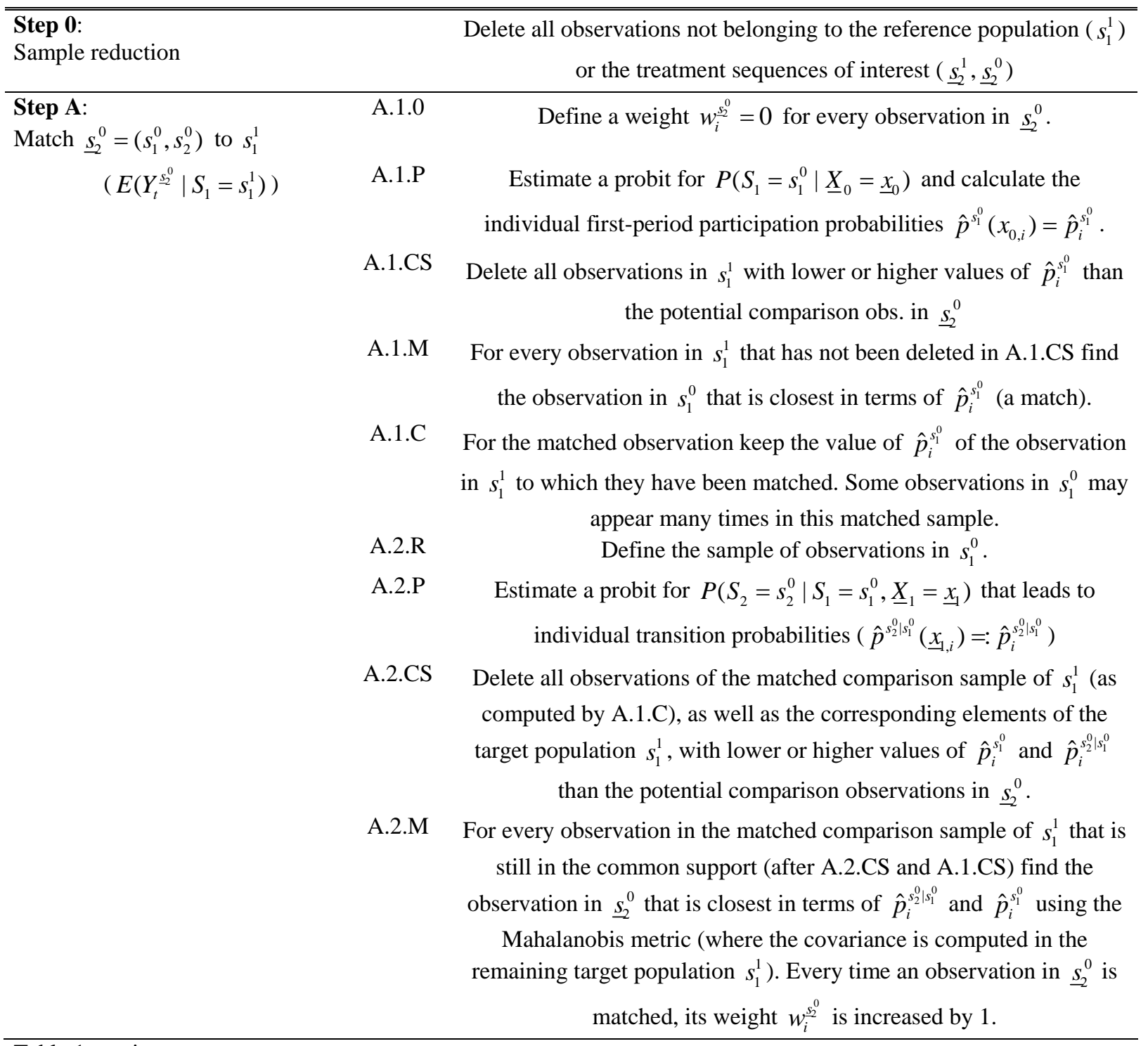

Table 1 continues on next page. 


\section{Table 1: Continued}

\begin{tabular}{|c|c|c|}
\hline $\begin{array}{l}\text { Step B: } \\
\text { Match } \underline{s}_{2}^{1}=\left(s_{1}^{1}, s_{2}^{1}\right) \text { to } s_{1}^{1}\end{array}$ & B.1.0 & Define a weight $w_{i}^{s_{2}^{1}}=0$ for every observation in $\underline{s}_{2}^{1}$. \\
\hline$\left(E\left(Y_{t}^{s_{2}^{1}} \mid S_{1}=s_{1}^{1}\right)\right)$ & B.2.R & $\begin{array}{c}\text { Reduce the sample to the observations in } s_{1}^{1} \text { that are in the common } \\
\text { support after the matching steps so far. }\end{array}$ \\
\hline & B.2.P & $\begin{array}{l}\text { Estimate a probit for } P\left(S_{2}=s_{2}^{1} \mid S_{1}=s_{1}^{1}, \underline{X}_{1}=\underline{x}_{1}\right) \text { that leads to } \\
\text { individual transition probabilities }\left(\hat{p}^{s_{2}^{1} \mid s_{1}^{1}}\left(\underline{x}_{1, i}\right)=: \hat{p}_{i}^{s_{2}^{1} \mid s_{1}^{1}}\right) \text {. }\end{array}$ \\
\hline
\end{tabular}

B.2.CS Delete all observations remaining in $s_{1}^{1}$ with lower or higher values of

$$
\hat{p}_{i}^{s_{2}^{1} \mid s_{1}^{1}} \text { than observations in } \underline{s}_{2}^{1} \text {. }
$$

B.2.M For every observation in $s_{1}^{1}$ not deleted in B.2.CS find the observation in $\underline{s}_{2}^{1}$ that is closest in terms of $\hat{p}_{i}^{s_{2}^{1} \mid s_{1}^{1}}$. Every time an observations in $\underline{s}_{2}^{1}$ is matched, its weight $w_{i}^{s_{2}^{1}}$ is increased by 1 .

Step C:

Joint common support
C.1 Reduce $w_{i}^{s_{2}^{1}}$ by 1 for every observation $i$ that is matched to an observation in $s_{1}^{1}$ deleted in A.1.CS or A.2.CS (this case it is not required if B.2.R is strictly enforced).

C.2 Reduce $w_{i}^{s_{2}^{0}}$ by 1 for every observation $i$ that is matched to an observation in $s_{1}^{1}$ deleted in B.2.CS (this case it is not required if

B.2.R is strictly enforced).

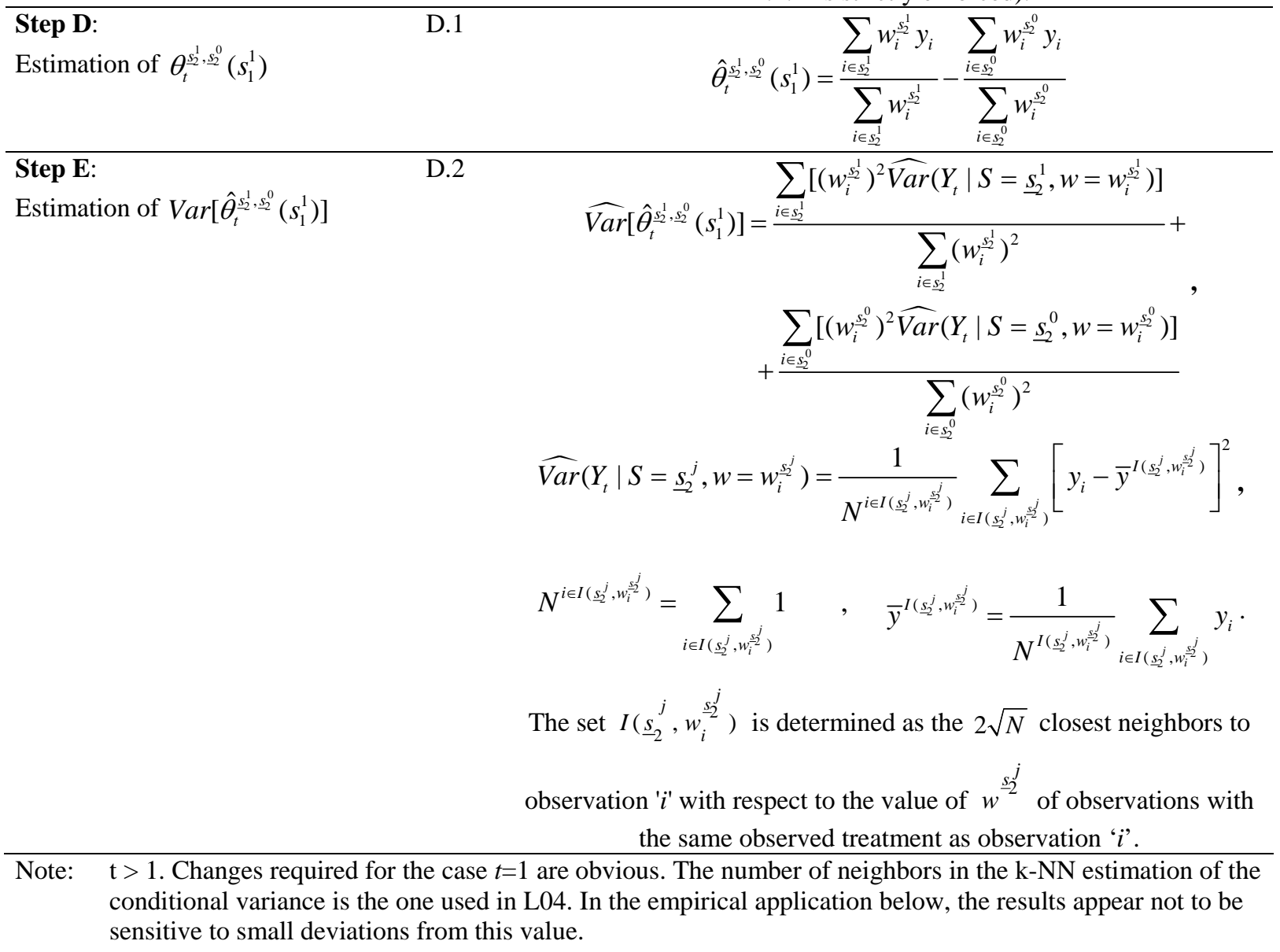


Table 2: Descriptive statistics for selected variables and selected subsamples

\begin{tabular}{|c|c|c|c|c|c|c|c|c|c|c|c|c|c|}
\hline \multirow[t]{3}{*}{ Variable } & \multirow[t]{3}{*}{ Type } & \multicolumn{12}{|c|}{ Subsample defined by treatment status in periods 3(1) up to 4(2) } \\
\hline & & \multicolumn{2}{|c|}{0} & \multicolumn{2}{|c|}{000000} & \multicolumn{2}{|c|}{1} & \multicolumn{2}{|c|}{1111} & \multicolumn{2}{|c|}{2} & \multicolumn{2}{|c|}{222222} \\
\hline & & mean & SD & mean & SD & mean & SD & mean & SD & mean & SD & mean & SD \\
\hline \multicolumn{14}{|c|}{ Monthly earnings in EUR } \\
\hline $\begin{array}{l}\text { Last } 10 \text { years } \\
\text { (average) }\end{array}$ & $\mathrm{C}$ & 1349 & 1789 & 1030 & 1089 & 4673 & 4071 & 4851 & 4074 & 5449 & 3883 & 5432 & 3895 \\
\hline $1(1)$ & $\mathrm{C}$ & 1095 & 1732 & 786 & 1028 & 4323 & 4137 & 4386 & 4156 & 5009 & 4040 & 4953 & 4067 \\
\hline $2(4)$ & $\mathrm{C}$ & 0 & 0 & 0 & 0 & 0 & 0 & 0 & 0 & 0 & 0 & 0 & 0 \\
\hline $4(1)$ & $\mathrm{C}$ & 358 & 1034 & 525 & 832 & 1337 & 3107 & 722 & 2246 & 1278 & 3093 & 444 & 1943 \\
\hline $9(4)$ & $\mathrm{C}$ & 1241 & 1933 & 768 & 1038 & 3964 & 4270 & 4040 & 4345 & 5229 & 4533 & 5091 & 4512 \\
\hline \multicolumn{14}{|c|}{ Unemployment in \% } \\
\hline $\begin{array}{l}\text { Total months in } \\
\text { last } 10 \text { years }\end{array}$ & $\mathrm{D}$ & 12 & 7 & 11 & 7 & 11 & 7 & 12 & 7 & 12 & 7 & 13 & 7 \\
\hline $1(1)$ & I & 10 & - & 9 & - & 6 & - & 7 & - & 5 & - & 6 & - \\
\hline 2(4) & I & 100 & - & 100 & - & 100 & - & 100 & - & 100 & - & 100 & - \\
\hline $4(1)$ & I & 54 & - & 23 & - & 60 & - & 65 & - & 60 & - & 78 & - \\
\hline $9(4)$ & I & 10 & - & 21 & - & 5 & - & 5 & - & 7 & - & 9 & - \\
\hline \multicolumn{14}{|c|}{ Employment in \% } \\
\hline $\begin{array}{l}\text { Total months in } \\
\text { last } 10 \text { years }\end{array}$ & $\mathrm{D}$ & 85 & 20 & 86 & 22 & 89 & 19 & 87 & 20 & 89 & 18 & 88 & 18 \\
\hline $1(1)$ & $\mathrm{I}$ & 78 & - & 76 & - & 90 & - & 87 & - & 90 & - & 89 & - \\
\hline 2(4) & I & 0 & - & 0 & - & 0 & - & 0 & - & 0 & - & 0 & - \\
\hline $4(1)$ & I & 31 & - & 49 & - & 32 & - & 27 & - & 35 & - & 17 & - \\
\hline $9(4)$ & I & 68 & - & 58 & - & 86 & - & 87 & - & 83 & - & 80 & - \\
\hline \multicolumn{14}{|c|}{ Labour market prospects as assessed by caseworker $(1,2,3,4)$} \\
\hline 2(4) & $\mathrm{D}$ & 2.8 & 1.1 & 3.1 & 1.0 & 2.7 & 1.1 & 2.6 & 1.1 & 2.4 & 1.2 & 2.5 & 1.2 \\
\hline $3(1)$ & $\mathrm{D}$ & 2.3 & 1.1 & 2.7 & 1.1 & 2.0 & 1.1 & 1.9 & 1.1 & 1.9 & 1.0 & 1.9 & 1.0 \\
\hline $4(1)$ & $\mathrm{D}$ & 2.6 & 1.1 & 3.4 & .8 & 2.5 & 1.1 & 2.3 & 1.1 & 2.4 & 1.2 & 2.1 & 1.1 \\
\hline \multicolumn{14}{|c|}{ Regional unemployment rate in \%-points (85 regions) } \\
\hline 2(4) & $\mathrm{D}$ & 12 & 5 & 12 & 5 & 12 & 5 & 12 & 5 & 12 & 5 & 12 & 5 \\
\hline $3(1)$ & $\mathrm{D}$ & 13 & 5 & 13 & 5 & 13 & 5 & 13 & 5 & 13 & 5 & 13 & 5 \\
\hline $4(1)$ & $\mathrm{D}$ & 15 & 27 & 14 & 5 & 14 & 5 & 15 & 5 & 14 & 5 & 14 & 5 \\
\hline \multicolumn{14}{|c|}{ Other variables } \\
\hline Age in 1(1), years & $\mathrm{D}$ & 40 & 6 & 39 & 6 & 41 & 6 & 41 & 6 & 40 & 6 & 40 & 6 \\
\hline Female & I & 41 & - & 45 & - & 36 & - & 39 & - & 27 & - & 28 & - \\
\hline Schooling (8-12) & $\mathrm{D}$ & 10 & 1.3 & 10 & 1.2 & 11 & 1.3 & 11 & 1.3 & 12 & .9 & 12 & .9 \\
\hline $\begin{array}{l}\text { Vocational } \\
\text { degree }(0,1,2)\end{array}$ & $\mathrm{D}$ & .8 & .5 & .8 & .5 & 1.3 & .7 & 1.4 & .7 & 1.6 & .6 & 1.6 & .6 \\
\hline Nationality (1-5) & D & 1.6 & 1.1 & 1.6 & 1.1 & 1.6 & 1.1 & 1.6 & 1.1 & 1.6 & 1.1 & 1.6 & 1.1 \\
\hline $\begin{array}{l}\text { Regional share of } \\
\text { service sector }\end{array}$ & $\mathrm{C}$ & 58 & 13 & 58 & 14 & 60 & 13 & 59 & 13 & 63 & 12 & 62 & 12 \\
\hline $\begin{array}{l}\text { Regional share of } \\
\text { production sector }\end{array}$ & $\mathrm{C}$ & 30 & 11 & 29 & 11 & 29 & 11 & 30 & 11 & 28 & 10 & 28 & 10 \\
\hline Sectoral UE rate & $\mathrm{C}$ & 12 & 4 & 12 & 18 & 12 & 19 & 12 & 4 & 13 & 4 & 13 & 4 \\
\hline $\begin{array}{l}\text { Occupational UE } \\
\text { rate }\end{array}$ & $\mathrm{C}$ & 12 & 21 & 11 & 5 & 11 & 21 & 12 & 5 & 13 & 4 & 13 & 4 \\
\hline Observations & & 69951 & - & 16871 & - & 8997 & - & 888 & - & 8665 & - & 3404 & - \\
\hline $\begin{array}{ll}\text { Note: } & \text { I: Binary } \\
& \text { SD: Stand } \\
& \text { observatio } \\
& \text { of only } 4 \\
& \text { there woul }\end{array}$ & indica & $\begin{array}{l}\text { r varial } \\
\text { iation } \mathrm{i}\end{array}$ & $\begin{array}{l}\text { ole }(0,1 \\
\text { n subsa } \\
\text { lete sa } \\
\text { of a se }\end{array}$ & $\begin{array}{l}\text {; D: } \mathrm{Di} \\
\text { mple. Fc } \\
\text { nple is } 1 \\
\text { quence } \\
\text { ions in } \mathrm{t}\end{array}$ & $\begin{array}{l}\text { crete } v \\
\text { r indica } \\
00,000 . \\
\text { f } 6 \text { peri } \\
\text { ne latte }\end{array}$ & $\begin{array}{l}\text { Iriable; } \\
\text { tor varia } \\
\text { For trea } \\
\text { gds as fo } \\
\text { group. I }\end{array}$ & $\begin{array}{l}\text { C: Cont } \\
\text { bles th } \\
\text { tment } 1 \\
\text { or treatn } \\
\text { Descrip }\end{array}$ & $\begin{array}{l}\text { nuous } \\
\text { share c } \\
\text { we sho } \\
\text { ents } 0 \\
\text { ive stat }\end{array}$ & $\begin{array}{l}\text { ariable } \\
\text { f ones }\end{array}$ & $\begin{array}{l}\text { mean: } \\
\% \text { is g } \\
\text { ample } \mathrm{t} \\
\text { cause } \mathrm{f} \\
\text { the var }\end{array}$ & $\begin{array}{l}\text { Tean i } \\
\text { ven. T } \\
\text { ased o } \\
\text { r this } \\
\text { ables }\end{array}$ & $\begin{array}{l}\text { ubsam } \\
\text { numb } \\
\text { a seque } \\
\text { ort pro }\end{array}$ & $\begin{array}{l}\text { e; } \\
\text { of } \\
\text { ce } \\
\text { am }\end{array}$ \\
\hline
\end{tabular}


Table 3: Earnings effects of program sequences estimated by sequential matching

\begin{tabular}{|c|c|c|c|c|c|c|c|c|c|c|c|c|}
\hline Year (quarter) & $4(4)$ & $7(4)$ & $9(4)$ & $4(4)$ & $7(4)$ & $9(4)$ & $4(4)$ & $7(4)$ & $9(4)$ & $4(4)$ & $7(4)$ & $9(4)$ \\
\hline Sequences $\underline{s}^{1}-\underline{s}^{0}$ & \multicolumn{3}{|c|}{$111002-000000$} & \multicolumn{3}{|c|}{$222001-000000$} & \multicolumn{3}{|c|}{$111002-222001$} & \multicolumn{3}{|c|}{$444003-000000$} \\
\hline$S\left(N_{s}\right)$ & \multicolumn{3}{|c|}{$1(5638)$} & \multicolumn{3}{|c|}{$2(5790)$} & \multicolumn{3}{|c|}{$1(7098)$} & \multicolumn{3}{|c|}{$4(6434)$} \\
\hline $\begin{array}{l}\text { Estimated outcome: } \\
E\left(Y_{t}^{\underline{s}^{1}} \mid S=s\right)\end{array}$ & $\begin{array}{l}1043 \\
(210)\end{array}$ & $\begin{array}{l}2597 \\
(250)\end{array}$ & $\begin{array}{l}2845 \\
(315)\end{array}$ & $\begin{array}{l}837 \\
(83)\end{array}$ & $\begin{array}{l}3746 \\
(281)\end{array}$ & 3746 & $\begin{array}{l}2168 \\
(288)\end{array}$ & $\begin{array}{l}4420 \\
(343)\end{array}$ & $\begin{array}{l}4950 \\
(354)\end{array}$ & $\begin{array}{l}217 \\
(31)\end{array}$ & $\begin{array}{l}897 \\
(70)\end{array}$ & $\begin{array}{l}697 \\
(66)\end{array}$ \\
\hline $\begin{array}{l}\text { Estimated outcome: } \\
E\left(Y_{t}^{\underline{s}^{0}} \mid S=s\right)\end{array}$ & $\begin{array}{l}1505 \\
(162)\end{array}$ & $\begin{array}{l}2122 \\
(182)\end{array}$ & $\begin{array}{l}2167 \\
(182)\end{array}$ & $\begin{array}{l}1921 \\
(258)\end{array}$ & $\begin{array}{l}2341 \\
(271)\end{array}$ & $\begin{array}{l}2537 \\
(292)\end{array}$ & $\begin{array}{l}1327 \\
(106)\end{array}$ & $\begin{array}{l}4535 \\
(317)\end{array}$ & $\begin{array}{l}4757 \\
(316)\end{array}$ & $\begin{array}{l}393 \\
(38)\end{array}$ & $\begin{array}{l}621 \\
(61)\end{array}$ & $\begin{array}{l}626 \\
(59)\end{array}$ \\
\hline Effect: $\theta_{t}^{s^{1}, s^{0}}(s)$ & $\begin{array}{l}-462 \\
(265)\end{array}$ & $\begin{array}{r}678 \\
(364)\end{array}$ & $\begin{array}{r}678 \\
(364)\end{array}$ & $\begin{array}{r}-1084 \\
(271)\end{array}$ & $\begin{array}{l}1404 \\
(390)\end{array}$ & $\begin{array}{l}1311 \\
(393)\end{array}$ & $\begin{array}{r}840 \\
(307)\end{array}$ & $\begin{array}{l}-115 \\
(468)\end{array}$ & $\begin{array}{c}192 \\
(475)\end{array}$ & $\begin{array}{l}-175 \\
(49)\end{array}$ & $\begin{array}{l}276 \\
(92)\end{array}$ & $\begin{array}{c}71 \\
(88) \\
\end{array}$ \\
\hline$S\left(N_{s}\right)$ & \multicolumn{3}{|c|}{$0(48050)$} & \multicolumn{3}{|c|}{$0(49121)$} & \multicolumn{3}{|c|}{$2(7732)$} & \multicolumn{3}{|c|}{$0(16861)$} \\
\hline$E\left(Y_{t}^{\underline{s}^{1}} \mid S=s\right)$ & $\begin{array}{l}509 \\
(78)\end{array}$ & $\begin{array}{l}1549 \\
(87)\end{array}$ & $\begin{array}{c}1482 \\
(99)\end{array}$ & $\begin{array}{l}246 \\
(101)\end{array}$ & $\begin{array}{l}1937 \\
(185)\end{array}$ & $\begin{array}{l}1971 \\
(186)\end{array}$ & $\begin{array}{l}2668 \\
(377)\end{array}$ & $\begin{array}{l}5074 \\
(418)\end{array}$ & $\begin{array}{l}5678 \\
(415)\end{array}$ & $\begin{array}{l}284 \\
(56)\end{array}$ & $\begin{array}{l}1032 \\
(105)\end{array}$ & $\begin{array}{l}950^{\prime} \\
(116)\end{array}$ \\
\hline$E\left(Y_{t}^{\underline{s}^{0}} \mid S=s\right)$ & $\begin{array}{l}729 \\
(29)\end{array}$ & $\begin{array}{l}1008 \\
(34)\end{array}$ & $\begin{array}{l}1054 \\
(34)\end{array}$ & $\begin{array}{l}742 \\
(28)\end{array}$ & $\begin{array}{l}1016 \\
(32)\end{array}$ & $\begin{array}{l}1065 \\
(34)\end{array}$ & $\begin{array}{l}1608 \\
(128)\end{array}$ & $\begin{array}{l}5152 \\
(275)\end{array}$ & $\begin{array}{l}5526 \\
(302)\end{array}$ & $\begin{array}{l}601 \\
(28)\end{array}$ & $\begin{array}{l}843 \\
(33)\end{array}$ & $\begin{array}{l}875 \\
(35)\end{array}$ \\
\hline$\theta_{t}^{\underline{s}^{1}, \underline{s}^{0}}(s)$ & $\begin{array}{l}-219 \\
(83)\end{array}$ & $\begin{array}{l}540 \\
(94)\end{array}$ & $\begin{array}{c}427 \\
(105)\end{array}$ & $\begin{array}{l}-496 \\
(104)\end{array}$ & $\begin{array}{c}920 \\
(188)\end{array}$ & $\begin{array}{r}906 \\
(189)\end{array}$ & $\begin{array}{l}1059 \\
(399)\end{array}$ & $\begin{array}{c}-78 \\
(501)\end{array}$ & $\begin{array}{l}152 \\
(513)\end{array}$ & $\begin{array}{l}-317 \\
(63)\end{array}$ & $\begin{array}{c}188 \\
(110)\end{array}$ & $\begin{array}{c}75 \\
(121) \\
\end{array}$ \\
\hline$\underline{s}^{1}-\underline{s}^{0}$ & \multicolumn{3}{|c|}{$111000-000000$} & \multicolumn{3}{|c|}{$222000-000000$} & \multicolumn{3}{|c|}{$111000-222000$} & \multicolumn{3}{|c|}{$444000-000000$} \\
\hline$S\left(N_{s}\right)$ & \multicolumn{3}{|c|}{$1(6773)$} & \multicolumn{3}{|c|}{$2(5893)$} & \multicolumn{3}{|c|}{$1(7844)$} & \multicolumn{3}{|c|}{$4(7056)$} \\
\hline$E\left(Y_{t}^{\underline{s}^{1}} \mid S=s\right)$ & $\begin{array}{c}1080 \\
(88)\end{array}$ & $\begin{array}{l}2691 \\
(152)\end{array}$ & $\begin{array}{l}2324 \\
(151)\end{array}$ & $\begin{array}{l}771 \\
(86)\end{array}$ & $\begin{array}{l}3654 \\
(320)\end{array}$ & $\begin{array}{l}3033 \\
(289)\end{array}$ & $\begin{array}{l}2331 \\
(191)\end{array}$ & $\begin{array}{l}4125 \\
(202)\end{array}$ & $\begin{array}{l}3715 \\
(209)\end{array}$ & $\begin{array}{l}271 \\
(30)\end{array}$ & $\begin{array}{l}606 \\
(42)\end{array}$ & $\begin{array}{l}680 \\
(54)\end{array}$ \\
\hline$E\left(Y_{t}^{\underline{s}^{0}} \mid S=s\right)$ & $\begin{array}{l}1382 \\
(134)\end{array}$ & $\begin{array}{l}1943 \\
(146)\end{array}$ & $\begin{array}{l}1992 \\
(152)\end{array}$ & $\begin{array}{l}1869 \\
(237)\end{array}$ & $\begin{array}{l}2277 \\
(251)\end{array}$ & $\begin{array}{l}2469 \\
(272)\end{array}$ & $\begin{array}{l}1291 \\
(198)\end{array}$ & $\begin{array}{l}4064 \\
(430)\end{array}$ & $\begin{array}{l}3506 \\
(397)\end{array}$ & $\begin{array}{l}420 \\
(39)\end{array}$ & $\begin{array}{l}643 \\
(58)\end{array}$ & $\begin{array}{l}655 \\
(57)\end{array}$ \\
\hline$\theta_{t}^{s^{1}, \underline{s}^{0}}(s)$ & $\begin{array}{l}-302 \\
(160)\end{array}$ & $\begin{array}{l}748 \\
(211)\end{array}$ & $\begin{array}{c}332 \\
(214)\end{array}$ & $\begin{array}{l}-1097 \\
(252)\end{array}$ & $\begin{array}{l}1377 \\
(407) \\
\end{array}$ & $\begin{array}{r}564 \\
(398)\end{array}$ & $\begin{array}{l}1039 \\
(275)\end{array}$ & $\begin{array}{c}60 \\
(475) \\
\end{array}$ & $\begin{array}{r}209 \\
(449) \\
\end{array}$ & $\begin{array}{l}-149 \\
(49)\end{array}$ & $\begin{array}{l}-37 \\
(72)\end{array}$ & $\begin{array}{c}23 \\
(79) \\
\end{array}$ \\
\hline$S\left(N_{s}\right)$ & \multicolumn{3}{|c|}{$0(67827)$} & \multicolumn{3}{|c|}{$0(56100)$} & \multicolumn{3}{|c|}{$2(7219)$} & \multicolumn{3}{|c|}{$0(31642)$} \\
\hline$E\left(Y_{t}^{\underline{s}^{1}} \mid S=s\right)$ & $\begin{array}{l}572 \\
(34)\end{array}$ & $\begin{array}{l}1432 \\
(51)\end{array}$ & $\begin{array}{l}1125 \\
(54)\end{array}$ & $\begin{array}{c}350 \\
(142)\end{array}$ & $\begin{array}{l}1620 \\
(285)\end{array}$ & $\begin{array}{l}1497 \\
(217)\end{array}$ & $\begin{array}{l}3085 \\
(321)\end{array}$ & $\begin{array}{l}5133 \\
(302)\end{array}$ & $\begin{array}{l}4481 \\
(320)\end{array}$ & $\begin{array}{l}383 \\
(139)\end{array}$ & $\begin{array}{l}721 \\
(156)\end{array}$ & $\begin{array}{l}859 \\
(190)\end{array}$ \\
\hline$E\left(Y_{t}^{\underline{s}^{0}} \mid S=s\right)$ & $\begin{array}{l}617 \\
(23)\end{array}$ & $\begin{array}{l}857 \\
(27)\end{array}$ & $\begin{array}{l}900 \\
(27)\end{array}$ & $\begin{array}{l}693 \\
(25)\end{array}$ & $\begin{array}{l}955 \\
(28)\end{array}$ & $\begin{array}{l}1001 \\
(29)\end{array}$ & $\begin{array}{l}1525 \\
(136)\end{array}$ & $\begin{array}{l}4589 \\
(327)\end{array}$ & $\begin{array}{l}3837 \\
(303)\end{array}$ & $\begin{array}{l}564 \\
(20)\end{array}$ & $\begin{array}{l}795 \\
(25)\end{array}$ & $\begin{array}{l}840 \\
(26)\end{array}$ \\
\hline$\theta_{t}^{\underline{s}^{1}, \underline{s}^{0}}(s)$ & $\begin{array}{l}-45 \\
(41)\end{array}$ & $\begin{array}{l}574 \\
(58)\end{array}$ & $\begin{array}{l}225 \\
(60)\end{array}$ & $\begin{array}{l}-343 \\
(144)\end{array}$ & $\begin{array}{r}665 \\
(287) \\
\end{array}$ & $\begin{array}{l}496 \\
(219)\end{array}$ & $\begin{array}{l}1559 \\
(349) \\
\end{array}$ & $\begin{array}{r}543 \\
(445) \\
\end{array}$ & $\begin{array}{r}644 \\
(441) \\
\end{array}$ & $\begin{array}{l}-180 \\
(140) \\
\end{array}$ & $\begin{array}{c}-73 \\
(158)\end{array}$ & $\begin{array}{c}19 \\
(192)\end{array}$ \\
\hline
\end{tabular}

Note: The first element of each sequence refers to period 3(1). $S$ defines the population for which the effects are estimated. $N_{s}$ is the number of remaining observations after adjusting the population $s$ for lack of common support. Estimated standard errors appear in parentheses below the estimates. Bold: Effect is significant at $1 \%$ level. Italics: Effect significant at $10 \%$ level. 
Table 4: The earnings effects of waiting estimated by sequential matching

\begin{tabular}{|c|c|c|c|c|c|c|c|c|c|c|c|c|}
\hline Year (quarter) & $4(4)$ & $7(4)$ & $9(4)$ & $4(4)$ & $7(4)$ & $9(4)$ & $4(4)$ & $7(4)$ & $9(4)$ & $4(4)$ & $7(4)$ & $9(4)$ \\
\hline Sequences $\underline{s}^{1}-\underline{s}^{0}$ & \multicolumn{3}{|c|}{$1-01$} & \multicolumn{3}{|c|}{$1-0001$} & \multicolumn{3}{|c|}{$1-00001$} & \multicolumn{3}{|c|}{$1-000001$} \\
\hline$S\left(N_{s}\right)$ & \multicolumn{3}{|c|}{$1(8833)$} & \multicolumn{3}{|c|}{$1(7816)$} & \multicolumn{3}{|c|}{$1(5172)$} & \multicolumn{3}{|c|}{$1(3405)$} \\
\hline $\begin{array}{l}\text { Estimated outcome: } \\
E\left(Y_{t}^{\underline{s}^{1}} \mid S=s\right)\end{array}$ & $\begin{array}{l}1805 \\
(36)\end{array}$ & $\begin{array}{c}3903 \\
(43)\end{array}$ & $\begin{array}{c}3862 \\
(44)\end{array}$ & $\begin{array}{l}1381 \\
(32)\end{array}$ & $\begin{array}{c}3255 \\
(42)\end{array}$ & $\begin{array}{c}3190 \\
(44)\end{array}$ & $\begin{array}{l}815 \\
(23)\end{array}$ & $\begin{array}{c}2066 \\
(34)\end{array}$ & $\begin{array}{l}1956 \\
(36)\end{array}$ & $\begin{array}{l}631 \\
(20)\end{array}$ & $\begin{array}{l}1587 \\
(28)\end{array}$ & $\begin{array}{l}1452 \\
(30)\end{array}$ \\
\hline $\begin{array}{l}\text { Estimated outcome: } \\
E\left(Y_{t}^{\underline{s^{0}}} \mid S=s\right)\end{array}$ & $\begin{array}{l}1698 \\
(100)\end{array}$ & $\begin{array}{l}3935 \\
(103)\end{array}$ & $\begin{array}{l}3818 \\
(109)\end{array}$ & $\begin{array}{l}1963 \\
(220)\end{array}$ & $\begin{array}{l}3304 \\
(203)\end{array}$ & $\begin{array}{l}3246 \\
(228)\end{array}$ & $\begin{array}{l}1214 \\
(155)\end{array}$ & $\begin{array}{l}2019 \\
(140)\end{array}$ & $\begin{array}{l}1802 \\
(143)\end{array}$ & $\begin{array}{l}555 \\
(69)\end{array}$ & $\begin{array}{c}1198 \\
(92)\end{array}$ & $\begin{array}{l}1179 \\
(101)\end{array}$ \\
\hline Effect: $\theta_{t}^{\underline{s}^{1}, \underline{s}^{0}}(s)$ & $\begin{array}{c}106 \\
(106) \\
\end{array}$ & $\begin{array}{c}-31 \\
(112)\end{array}$ & $\begin{array}{c}44 \\
(118)\end{array}$ & $\begin{array}{l}-581 \\
(222) \\
\end{array}$ & $\begin{array}{c}-49 \\
(207) \\
\end{array}$ & $\begin{array}{c}-56 \\
(232) \\
\end{array}$ & $\begin{array}{l}-398 \\
(157)\end{array}$ & $\begin{array}{c}47 \\
(144)\end{array}$ & $\begin{array}{c}153 \\
(148)\end{array}$ & $\begin{array}{c}76 \\
(72) \\
-\end{array}$ & $\begin{array}{l}388 \\
(96)\end{array}$ & $\begin{array}{c}272 \\
(106) \\
\end{array}$ \\
\hline$S\left(N_{s}\right)$ & \multicolumn{3}{|c|}{$0(69316)$} & \multicolumn{3}{|c|}{$0(69219)$} & \multicolumn{3}{|c|}{$0(57471)$} & \multicolumn{3}{|c|}{$0(44463)$} \\
\hline$E\left(Y_{t}^{\underline{s}^{1}} \mid S=s\right)$ & $\begin{array}{l}506 \\
(13)\end{array}$ & $\begin{array}{l}1362 \\
(17)\end{array}$ & $\begin{array}{l}1209 \\
(19)\end{array}$ & $\begin{array}{l}490 \\
(12)\end{array}$ & $\begin{array}{l}1328 \\
(18)\end{array}$ & $\begin{array}{l}1174 \\
(19)\end{array}$ & $\begin{array}{l}460 \\
(12)\end{array}$ & $\begin{array}{l}1256 \\
(17)\end{array}$ & $\begin{array}{l}1101 \\
(19)\end{array}$ & $\begin{array}{l}422 \\
(12)\end{array}$ & $\begin{array}{l}1170 \\
(17)\end{array}$ & $\begin{array}{l}1004 \\
(20)\end{array}$ \\
\hline$E\left(Y_{t}^{\underline{s}^{0}} \mid S=s\right)$ & $\begin{array}{l}463 \\
(15)\end{array}$ & $\begin{array}{l}1374 \\
(19)\end{array}$ & $\begin{array}{l}1212 \\
(19)\end{array}$ & $\begin{array}{l}564 \\
(33)\end{array}$ & $\begin{array}{l}1476 \\
(38)\end{array}$ & $\begin{array}{l}1313 \\
(44)\end{array}$ & $\begin{array}{l}606 \\
(43)\end{array}$ & $\begin{array}{c}1392 \\
(61)\end{array}$ & $\begin{array}{l}1257 \\
(58)\end{array}$ & $\begin{array}{l}447 \\
(55)\end{array}$ & $\begin{array}{l}1021 \\
(87)\end{array}$ & $\begin{array}{l}972 \\
(91)\end{array}$ \\
\hline$\theta_{t}^{\underline{s}^{1}, \underline{s}^{0}}(s)$ & $\begin{array}{c}43 \\
(19)\end{array}$ & $\begin{array}{l}-12 \\
(25)\end{array}$ & $\begin{array}{c}-2 \\
(27)\end{array}$ & $\begin{array}{l}-74 \\
(35)\end{array}$ & $\begin{array}{c}-151 \\
(41)\end{array}$ & $\begin{array}{c}-139 \\
(48)\end{array}$ & $\begin{array}{l}-145 \\
(45)\end{array}$ & $\begin{array}{c}-136 \\
(63)\end{array}$ & $\begin{array}{c}-156 \\
(61)\end{array}$ & $\begin{array}{l}-25 \\
(56)\end{array}$ & $\begin{array}{l}149 \\
(88)\end{array}$ & $\begin{array}{c}31 \\
(93)\end{array}$ \\
\hline$\underline{s}^{1}-\underline{s}^{0}$ & \multicolumn{3}{|c|}{$3-0003$} & \multicolumn{3}{|c|}{$33-00033$} & \multicolumn{3}{|c|}{ 333-000333 } & \multicolumn{3}{|c|}{ 4-000004 } \\
\hline$S\left(N_{s}\right)$ & \multicolumn{3}{|c|}{$3(4902)$} & \multicolumn{3}{|c|}{$3(4895)$} & \multicolumn{3}{|c|}{$3(4861)$} & \multicolumn{3}{|c|}{$4(4340)$} \\
\hline$E\left(Y_{t}^{\underline{s}^{1}} \mid S=s\right)$ & $\begin{array}{l}611 \\
(10)\end{array}$ & $\begin{array}{l}749 \\
(13)\end{array}$ & $\begin{array}{l}707 \\
(13)\end{array}$ & $\begin{array}{l}622 \\
(10)\end{array}$ & $\begin{array}{l}760 \\
(13)\end{array}$ & $\begin{array}{l}713 \\
(13)\end{array}$ & $\begin{array}{l}649 \\
(13)\end{array}$ & $\begin{array}{l}768 \\
(15)\end{array}$ & $\begin{array}{l}727 \\
(17)\end{array}$ & $\begin{array}{l}262 \\
(9)\end{array}$ & $\begin{array}{l}782 \\
(13)\end{array}$ & $\begin{array}{l}705 \\
(14)\end{array}$ \\
\hline$E\left(Y_{t}^{\underline{s}^{0}} \mid S=s\right)$ & $\begin{array}{l}516 \\
(24)\end{array}$ & $\begin{array}{l}845 \\
(27)\end{array}$ & $\begin{array}{l}728 \\
(37)\end{array}$ & $\begin{array}{l}526 \\
(25)\end{array}$ & $\begin{array}{l}867 \\
(30)\end{array}$ & $\begin{array}{l}744 \\
(40)\end{array}$ & $\begin{array}{l}541 \\
(30)\end{array}$ & $\begin{array}{l}908 \\
(35)\end{array}$ & $\begin{array}{l}749 \\
(38)\end{array}$ & $\begin{array}{c}261 \\
(289)\end{array}$ & $\begin{array}{c}624 \\
(295)\end{array}$ & $\begin{array}{l}809 \\
(446)\end{array}$ \\
\hline$\theta_{t}^{\underline{s}^{1}, \underline{s}^{0}}(s)$ & $\begin{array}{c}95 \\
(26)\end{array}$ & $\begin{array}{l}-95 \\
(29)\end{array}$ & $\begin{array}{l}-21 \\
(39)\end{array}$ & $\begin{array}{c}96 \\
(27)\end{array}$ & $\begin{array}{r}-106 \\
(33) \\
\end{array}$ & $\begin{array}{r}-31 \\
(42)\end{array}$ & $\begin{array}{l}108 \\
(32)\end{array}$ & $\begin{array}{r}-139 \\
(38) \\
\end{array}$ & $\begin{array}{l}-22 \\
(42)\end{array}$ & $\begin{array}{c}0 \\
(289)\end{array}$ & $\begin{array}{r}158 \\
(296) \\
\end{array}$ & $\begin{array}{l}-104 \\
(447) \\
\end{array}$ \\
\hline$S\left(N_{s}\right)$ & \multicolumn{3}{|c|}{$0(65673)$} & \multicolumn{3}{|c|}{$0(65572)$} & \multicolumn{3}{|c|}{$0(64177)$} & \multicolumn{3}{|c|}{$0(20887)$} \\
\hline$E\left(Y_{t}^{\underline{s}^{1}} \mid S=s\right)$ & $\begin{array}{l}663 \\
(22)\end{array}$ & $\begin{array}{l}808 \\
(32)\end{array}$ & $\begin{array}{l}782 \\
(32)\end{array}$ & $\begin{array}{l}639 \\
(23)\end{array}$ & $\begin{array}{l}812 \\
(32)\end{array}$ & $\begin{array}{l}783 \\
(31)\end{array}$ & $\begin{array}{l}687 \\
(22)\end{array}$ & $\begin{array}{l}820 \\
(31)\end{array}$ & $\begin{array}{l}815 \\
(33)\end{array}$ & $\begin{array}{l}311 \\
(55)\end{array}$ & $\begin{array}{c}884 \\
(100)\end{array}$ & $\begin{array}{l}781 \\
(100)\end{array}$ \\
\hline$E\left(Y_{t}^{\underline{s}^{0}} \mid S=s\right)$ & $\begin{array}{l}544 \\
(21)\end{array}$ & $\begin{array}{l}902 \\
(26)\end{array}$ & $\begin{array}{l}792 \\
(28)\end{array}$ & $\begin{array}{l}542 \\
(23)\end{array}$ & $\begin{array}{l}912 \\
(27)\end{array}$ & $\begin{array}{l}795 \\
(32)\end{array}$ & $\begin{array}{l}557 \\
(25)\end{array}$ & $\begin{array}{l}932 \\
(28)\end{array}$ & $\begin{array}{l}788 \\
(32)\end{array}$ & $\begin{array}{c}345 \\
(116)\end{array}$ & $\begin{array}{c}599 \\
(116)\end{array}$ & $\begin{array}{l}620 \\
(174)\end{array}$ \\
\hline$\theta_{t}^{\underline{s}^{1}, \underline{s}^{0}}(s)$ & $\begin{array}{r}89 \\
(31) \\
\end{array}$ & $\begin{array}{l}-93 \\
(41) \\
\end{array}$ & $\begin{array}{l}-10 \\
(42) \\
\end{array}$ & $\begin{array}{r}95 \\
(32) \\
\end{array}$ & $\begin{array}{l}-101 \\
(42) \\
\end{array}$ & $\begin{array}{l}-12 \\
(45) \\
\end{array}$ & $\begin{array}{l}128 \\
(33) \\
\end{array}$ & $\begin{array}{r}-112 \\
(42) \\
\end{array}$ & $\begin{array}{r}27 \\
(47) \\
\end{array}$ & $\begin{array}{c}-34 \\
(128) \\
\end{array}$ & $\begin{array}{r}285 \\
(153) \\
\end{array}$ & $\begin{array}{r}161 \\
(201) \\
\end{array}$ \\
\hline
\end{tabular}

Note: $\quad$ The first element of each sequence refers to period 3(1). $S$ defines the population for which the effects are estimated. $N_{s}$ is the number of remaining observations after adjusting the population $s$ for lack of common support. Estimated standard errors appear in parentheses below the estimates. Bold: Effect is significant at $1 \%$ level. Italics: Effect significant at $10 \%$ level. 
Table 5: The earnings effects of the duration of the program estimated by sequential matching

\begin{tabular}{|c|c|c|c|c|c|c|c|c|c|c|c|c|}
\hline Year (quarter) & $4(4)$ & $7(4)$ & $9(4)$ & $4(4)$ & $7(4)$ & $9(4)$ & $4(4)$ & $7(4)$ & $9(4)$ & $4(4)$ & $7(4)$ & $9(4)$ \\
\hline Sequences $\underline{s}^{1}-\underline{s}^{0}$ & \multicolumn{3}{|c|}{$1-11$} & \multicolumn{3}{|c|}{$1-111$} & \multicolumn{3}{|c|}{$1-1111$} & \multicolumn{3}{|c|}{$11-1111$} \\
\hline$S\left(N_{s}\right)$ & \multicolumn{3}{|c|}{$1(8989)$} & \multicolumn{3}{|c|}{$1(8957)$} & \multicolumn{3}{|c|}{$1(8813)$} & \multicolumn{3}{|c|}{$1(8810)$} \\
\hline $\begin{array}{l}E\left(Y_{t}^{\underline{s}^{1}} \mid S=s\right)\end{array}$ & $\begin{array}{c}1885 \\
(36)\end{array}$ & $\begin{array}{c}4002 \\
(43)\end{array}$ & $\begin{array}{c}3965 \\
(45)\end{array}$ & $\begin{array}{c}1885 \\
(36)\end{array}$ & $\begin{array}{c}4003 \\
(44)\end{array}$ & $\begin{array}{c}3965 \\
(45)\end{array}$ & $\begin{array}{c}1882 \\
(36)\end{array}$ & $\begin{array}{c}4006 \\
(44)\end{array}$ & $\begin{array}{c}3971 \\
(45)\end{array}$ & $\begin{array}{c}1955 \\
(45)\end{array}$ & $\begin{array}{c}4133 \\
(54)\end{array}$ & $\begin{array}{c}4036 \\
(56)\end{array}$ \\
\hline $\begin{array}{l}\text { Estimated outcome: } \\
E\left(Y_{t}^{s^{0}} \mid S=s\right)\end{array}$ & $\begin{array}{l}1958 \\
(44)\end{array}$ & $\begin{array}{l}4101 \\
(53)\end{array}$ & $\begin{array}{c}4002 \\
(55)\end{array}$ & $\begin{array}{c}2073 \\
(71)\end{array}$ & $\begin{array}{c}4248 \\
(82)\end{array}$ & $\begin{array}{l}4110 \\
(87)\end{array}$ & $\begin{array}{l}1948 \\
(174)\end{array}$ & $\begin{array}{l}4341 \\
(205)\end{array}$ & $\begin{array}{l}4290 \\
(212)\end{array}$ & $\begin{array}{l}2008 \\
(166)\end{array}$ & $\begin{array}{l}4349 \\
(194)\end{array}$ & $\begin{array}{l}4151 \\
\text { (199) }\end{array}$ \\
\hline Effect: $\theta_{t}^{\frac{s^{1}}{s^{0}} \underline{0}^{0}}(s)$ & $\begin{array}{l}-72 \\
(57)\end{array}$ & $\begin{array}{l}-99 \\
(69)\end{array}$ & $\begin{array}{l}-37 \\
(71)\end{array}$ & $\begin{array}{l}-187 \\
(79)\end{array}$ & $\begin{array}{l}-245 \\
(93)\end{array}$ & $\begin{array}{l}-144 \\
(97)\end{array}$ & $\begin{array}{c}-65 \\
(178)\end{array}$ & $\begin{array}{l}-334 \\
(209)\end{array}$ & $\begin{array}{l}-319 \\
(217)\end{array}$ & $\begin{array}{c}-53 \\
(172)\end{array}$ & $\begin{array}{l}-215 \\
(201)\end{array}$ & $\begin{array}{l}-114 \\
(207)\end{array}$ \\
\hline$\underline{s}^{1}-\underline{s}^{0}$ & \multicolumn{3}{|c|}{$10-110$} & \multicolumn{3}{|c|}{$110-1110$} & \multicolumn{3}{|c|}{$10-11110$} & \multicolumn{3}{|c|}{$110-11110$} \\
\hline$s\left(N_{s}\right)$ & \multicolumn{3}{|c|}{$1(8973)$} & \multicolumn{3}{|c|}{$1(8935)$} & \multicolumn{3}{|c|}{$1(8757)$} & \multicolumn{3}{|c|}{$1(8763)$} \\
\hline $\begin{array}{l}E\left(Y_{t}^{S^{s^{1}}} \mid S=s\right) \\
E\left(Y_{t}^{s^{s^{0}}} \mid S=s\right)\end{array}$ & $\begin{array}{c}1570 \\
(83) \\
1942 \\
(71)\end{array}$ & $\begin{array}{c}3583 \\
(111) \\
3936 \\
(82)\end{array}$ & $\begin{array}{c}3767 \\
(114) \\
3900 \\
(84)\end{array}$ & $\begin{array}{c}1852 \\
(68) \\
2056 \\
(77)\end{array}$ & $\begin{array}{c}3915 \\
(83) \\
4244 \\
(94)\end{array}$ & $\begin{array}{c}3858 \\
(85) \\
4135 \\
(98)\end{array}$ & $\begin{array}{c}-1628 \\
(91) \\
1995 \\
(174)\end{array}$ & $\begin{array}{l}3514 \\
(112) \\
4318 \\
(204)\end{array}$ & $\begin{array}{l}3726 \\
(117) \\
4251 \\
(212)\end{array}$ & $\begin{array}{l}1855 \\
(67) \\
1973 \\
(166)\end{array}$ & $\begin{array}{l}3950 \\
(82) \\
4288 \\
(198)\end{array}$ & $\begin{array}{c}3876 \\
(83) \\
4179 \\
(203)\end{array}$ \\
\hline$\theta_{t}^{s^{1}, s^{0}}(s)$ & $\begin{array}{l}-371 \\
(109)\end{array}$ & $\begin{array}{l}-352 \\
(138) \\
\end{array}$ & $\begin{array}{l}-133 \\
(142)\end{array}$ & $\begin{array}{l}-203 \\
(103)\end{array}$ & $\begin{array}{l}-328 \\
(125) \\
\end{array}$ & $\begin{array}{l}-276 \\
(130)\end{array}$ & $\begin{array}{l}-336 \\
(196)\end{array}$ & $\begin{array}{r}-803 \\
(233) \\
\end{array}$ & $\begin{array}{l}-524 \\
(243)\end{array}$ & $\begin{array}{l}-117 \\
(179)\end{array}$ & $\begin{array}{l}-338 \\
(215) \\
\end{array}$ & $\begin{array}{l}-302 \\
(219)\end{array}$ \\
\hline
\end{tabular}

Note: The first element of each sequence refers to period 3(1). $S$ defines the population for which the effects are estimated. $N_{s}$ is the number of remaining observations after adjusting the population $s$ for lack of common support. Estimated standard errors appear in parentheses below the estimates. Bold: Effect is significant at $1 \%$ level. Italics: Effect significant at $10 \%$ level. 
Table 6: The comparison with static matching - earnings and employment in period 9(4)

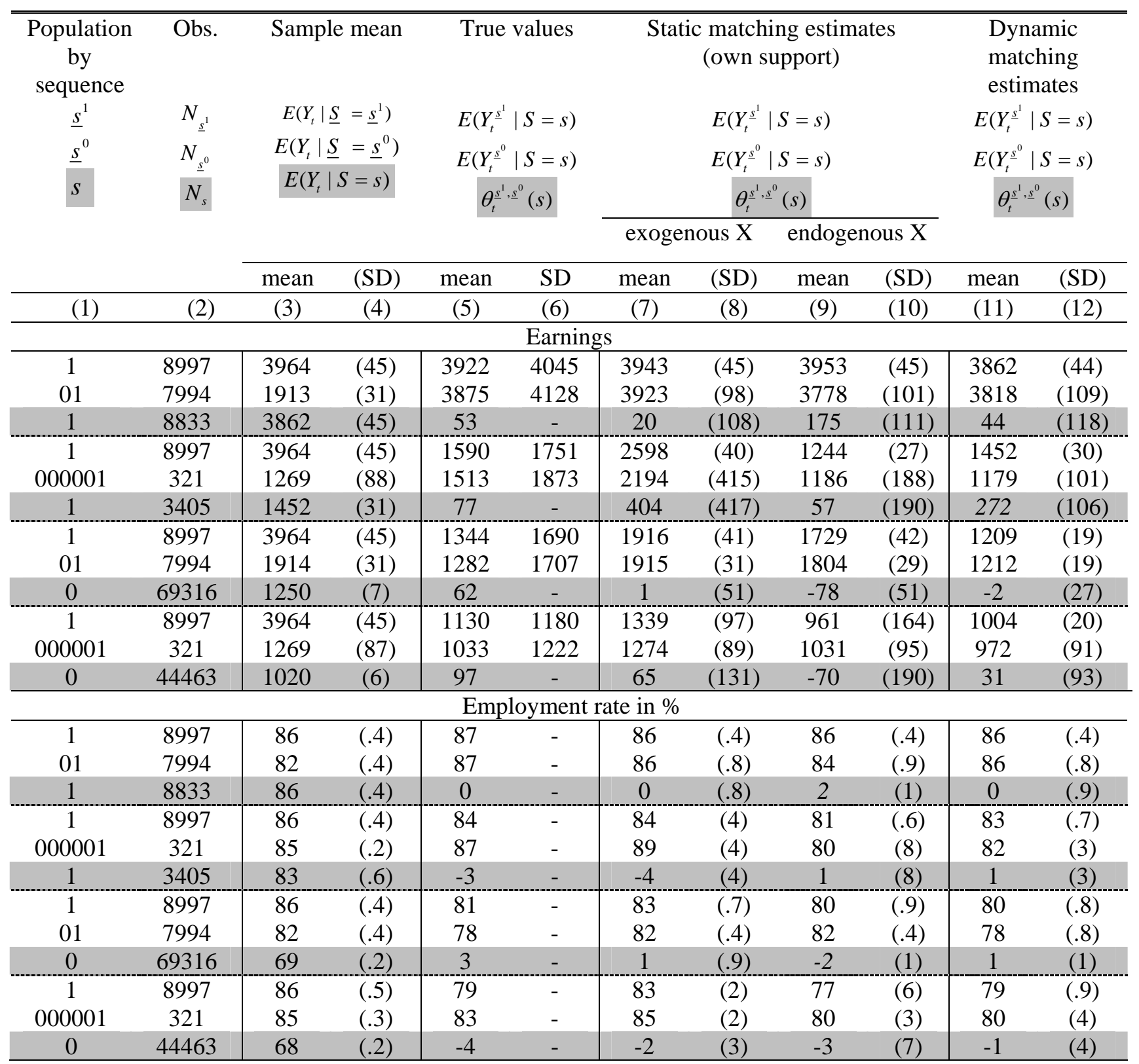

Note: The first element of each sequence refers to period 3(1). $N_{s}$ is the sample size after imposing common support. Estimated standard errors appear in parentheses. Bold: Effect is significant at $1 \%$ level. Italics: Effect significant at $10 \%$ level. ( $S D$ ) denotes the estimated standard error of the estimator, whereas $S D$ (without parentheses) denotes the standard deviation in the sample (not given for the binary outcome). True values and number of observations of the target population are given for the common support of the dynamic matching estimator. 
Table 7: The issue of common support-earnings in 9(4)

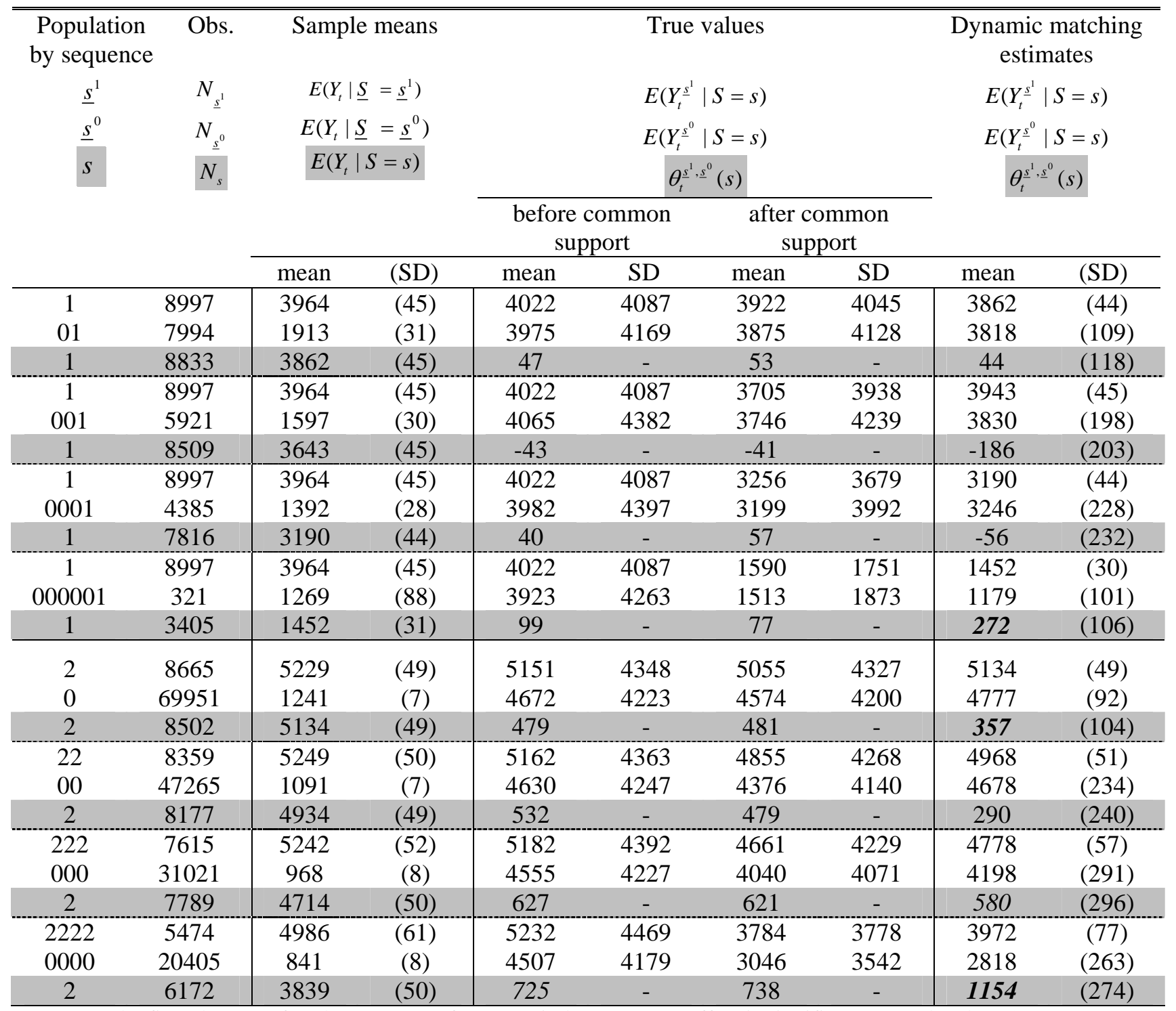

Note: $\quad$ The first element of each sequence refers to period 3(1). Bold: Effect is significant at 1\% level. Italics: Effect significant at $10 \%$ level. $N_{s}$ is the sample size after imposing common support. (SD) denotes the estimated standard error of the estimator, whereas $S D$ (without parentheses) denotes the standard deviation in the sample. 
Table 8: The importance and danger of including a rich set of covariates - earnings and employment in 9(4)

\begin{tabular}{|c|c|c|c|c|c|c|c|c|c|c|c|}
\hline \multirow{6}{*}{$\begin{array}{c}\text { Population } \\
\text { by } \\
\text { sequence } \\
\underline{s}^{1} \\
\underline{s}^{0} \\
S\end{array}$} & \multirow{6}{*}{$\begin{array}{l}\text { Obs. } \\
N_{\underline{s}^{1}} \\
N_{\underline{s}^{0}} \\
N_{s}\end{array}$} & \multicolumn{2}{|c|}{ Sample means } & \multicolumn{4}{|c|}{ True values } & \multicolumn{4}{|c|}{ Dynamic matching estimates } \\
\hline & & \multirow{3}{*}{\multicolumn{2}{|c|}{$\begin{array}{c}E\left(Y_{t} \mid \underline{S}=\underline{s}^{1}\right) \\
E\left(Y_{t} \mid \underline{S}=\underline{s}^{0}\right) \\
E\left(Y_{t} \mid S=s\right)\end{array}$}} & \multirow{3}{*}{\multicolumn{4}{|c|}{$\begin{array}{c}E\left(Y_{t}^{\underline{s}^{1}} \mid S=s\right) \\
E\left(Y_{t}^{\underline{s}^{0}} \mid S=s\right) \\
\theta_{t}^{\underline{s}^{1}, \underline{s}^{0}}(s)\end{array}$}} & \multirow{3}{*}{\multicolumn{4}{|c|}{$\begin{array}{c}E\left(Y_{t}^{\underline{s}^{1}} \mid S=s\right) \\
E\left(Y_{t}^{\underline{s}^{0}} \mid S=s\right) \\
\theta_{t}^{s^{1}, \underline{s}^{0}}(s)\end{array}$}} \\
\hline & & & & & & & & & & & \\
\hline & & & & & & & & & & & \\
\hline & & & & \multicolumn{2}{|c|}{ few $X$} & \multicolumn{2}{|c|}{ all $\mathrm{X}$} & \multicolumn{2}{|c|}{ few $X$} & \multicolumn{2}{|c|}{ all $\mathrm{X}$} \\
\hline & & mean & (SD) & mean & SD & mean & SD & mean & (SD) & mean & (SD) \\
\hline \multicolumn{12}{|c|}{ Earnings } \\
\hline 1 & 8997 & 3964 & (45) & 3983 & 4071 & 3922 & 4045 & 3925 & (45) & 3862 & (44) \\
\hline 01 & 7994 & 1913 & (31) & 3936 & 4151 & 3875 & 4128 & 3663 & (100) & 3818 & (109) \\
\hline 1 (all X) & 8833 & 3862 & (45) & 47 & - & 53 & - & 261 & (110) & 44 & (118) \\
\hline 1 & 8997 & 3964 & (45) & 1852 & 2372 & 1590 & 1751 & 1745 & (36) & 1452 & (30) \\
\hline 000001 & 321 & 1269 & (88) & 1770 & 2604 & 1513 & 1873 & 1320 & (140) & 1179 & (101) \\
\hline 1 (all X) & 3405 & 1452 & (31) & 82 & - & 77 & - & 425 & (144) & 272 & (106) \\
\hline 1 & 8997 & 3964 & (45) & 1349 & 1696 & 1344 & 1690 & 1324 & (23) & 1209 & (19) \\
\hline 01 & 7994 & 1913 & (31) & 1287 & 1713 & 1282 & 1707 & 1272 & (21) & 1212 & (19) \\
\hline $0($ all X) & 69316 & 3862 & (45) & 62 & - & 62 & - & 52 & (31) & -2 & (27) \\
\hline 1 & 8997 & 3964 & (45) & 1140 & 1254 & 1130 & 1180 & 1065 & (21) & 1004 & (20) \\
\hline 000001 & 321 & 1269 & (88) & 1251 & 1038 & 1033 & 1222 & 1080 & (120) & 972 & (91) \\
\hline 0 (all X) & 44463 & 1452 & (31) & -111 & - & 97 & - & -15 & (122) & 31 & (93) \\
\hline \multicolumn{12}{|c|}{ Employment rate in \% } \\
\hline 1 & 8997 & 86 & - & 87 & - & 87 & - & 86 & $(.3)$ & 86 & $(.4)$ \\
\hline 01 & 7994 & 82 & - & 85 & - & 87 & - & 85 & (.8) & 86 & (.8) \\
\hline 1 (all X) & 8833 & 86 & - & 2 & - & 0 & - & 1 & (.9) & 0 & (.9) \\
\hline 1 & 8997 & 86 & - & 84 & - & 84 & - & 83 & $(.5)$ & 83 & $(.7)$ \\
\hline 000001 & 321 & 85 & - & 86 & - & 87 & - & 78 & (4) & 82 & (3) \\
\hline 1 (all X) & 3405 & 83 & - & -2 & - & -3 & - & 4 & (5) & 1 & (3) \\
\hline 1 & 8997 & 86 & - & 81 & - & 81 & - & 80 & $(.8)$ & 80 & $(.8)$ \\
\hline 01 & 7994 & 82 & - & 78 & - & 78 & - & 79 & $(.7)$ & 78 & $(.8)$ \\
\hline $0($ all X) & 69316 & 69 & - & 3 & - & 3 & - & 1 & (1) & 1 & (1) \\
\hline 1 & 8997 & 86 & - & 79 & - & 79 & - & 79 & $(.9)$ & 79 & $(.9)$ \\
\hline 000001 & 321 & 85 & - & 83 & - & 83 & - & 77 & (4) & 80 & (4) \\
\hline 0 (all X) & 44463 & 68 & - & -4 & - & -4 & - & 2 & (4) & -1 & (4) \\
\hline
\end{tabular}

Note: The first element of each sequence refers to period 3(1). $N_{s}$ is the sample size after imposing common support. Bold: Effect is significant at 1\% level. Italics: Effect significant at $10 \%$ level. (SD) denotes the estimated standard error of the estimator, whereas $S D$ (without parentheses) denotes the standard deviation in the sample (not given for the binary outcome). Sample means and sample sizes after common support are those relating to the common support obtained for the estimation with the full set of covariates. 
Table A.1a: Mean and standard deviation of potential earnings in 7(4) in selected subsamples

\begin{tabular}{|c|c|c|c|c|c|c|c|c|c|c|}
\hline \multirow[t]{3}{*}{ Sequence } & \multicolumn{10}{|c|}{ Subsample (treatment state in period 3(1)) } \\
\hline & \multicolumn{2}{|c|}{0} & \multicolumn{2}{|c|}{1} & \multicolumn{2}{|c|}{2} & \multicolumn{2}{|c|}{3} & \multicolumn{2}{|c|}{4} \\
\hline & mean & SD & mean & SD & mean & SD & mean & SD & mean & SD \\
\hline 000000 & 933 & 1587 & 3613 & 4108 & 4378 & 4169 & 624 & 796 & 542 & 782 \\
\hline 01 & 1432 & 1588 & 4055 & 3975 & 4815 & 4023 & 1121 & 877 & 1026 & 838 \\
\hline 001 & 1506 & 1735 & 4209 & 4321 & 5000 & 4316 & 1172 & 959 & 1079 & 941 \\
\hline 0001 & 1342 & 1722 & 4089 & 4320 & 4830 & 4384 & 1013 & 924 & 923 & 911 \\
\hline 000001 & 1283 & 1720 & 3936 & 4239 & 4724 & 4309 & 955 & 935 & 858 & 889 \\
\hline 1 & 1470 & 1581 & 4073 & 3968 & 4822 & 3920 & 1157 & 858 & 1062 & 828 \\
\hline 11 & 1481 & 1557 & 4105 & 3933 & 4858 & 3967 & 1164 & 867 & 1070 & 838 \\
\hline 111 & 1500 & 1588 & 4166 & 4012 & 4924 & 4042 & 1179 & 885 & 1084 & 857 \\
\hline 1111 & 1510 & 1617 & 4216 & 4097 & 4977 & 4128 & 1186 & 902 & 1089 & 872 \\
\hline 10 & 1432 & 1488 & 4005 & 3781 & 4683 & 3778 & 1129 & 832 & 1035 & 797 \\
\hline 110 & 1498 & 1570 & 4094 & 3905 & 4784 & 3906 & 1148 & 853 & 1054 & 822 \\
\hline 1110 & 1497 & 1583 & 4150 & 3995 & 4908 & 4024 & 1177 & 832 & 1089 & 872 \\
\hline 11110 & 1517 & 1615 & 4297 & 4176 & 4968 & 4120 & 1194 & 903 & 1097 & 872 \\
\hline 111000 & 1337 & 1661 & 4102 & 4208 & 4885 & 4236 & 1009 & 880 & 913 & 869 \\
\hline 111002 & 1440 & 1685 & 3781 & 4157 & 4406 & 4329 & 1173 & 1074 & 1104 & 1069 \\
\hline 2 & 1793 & 1777 & 4338 & 4214 & 4973 & 4311 & 1505 & 1152 & 1456 & 1173 \\
\hline 22 & 1795 & 1783 & 4351 & 4232 & 4989 & 4328 & 2263 & 2625 & 1457 & 1176 \\
\hline 222 & 1800 & 1796 & 4377 & 4266 & 5017 & 4359 & 1510 & 1162 & 1459 & 1183 \\
\hline 2222 & 1802 & 1830 & 4437 & 4361 & 5086 & 4445 & 1507 & 1179 & 1454 & 1200 \\
\hline 222000 & 1657 & 1723 & 4197 & 4152 & 4841 & 4252 & 1369 & 1080 & 1326 & 1107 \\
\hline 222001 & 2041 & 1867 & 4567 & 4304 & 5254 & 4424 & 1726 & 1186 & 1669 & 1199 \\
\hline 3 & 1056 & 1655 & 3829 & 4295 & 4593 & 4356 & 754 & 870 & 655 & 847 \\
\hline 33 & 1057 & 1661 & 3838 & 4310 & 4603 & 4371 & 1570 & 2624 & 655 & 850 \\
\hline 333 & 1065 & 1676 & 3867 & 4354 & 4635 & 4412 & 1581 & 2648 & 660 & 857 \\
\hline 0003 & 1067 & 1707 & 3802 & 4398 & 4589 & 4511 & 1574 & 2671 & 686 & 873 \\
\hline 00033 & 1068 & 1713 & 3812 & 4419 & 4601 & 4534 & 755 & 878 & 686 & 877 \\
\hline 000333 & 1066 & 1731 & 3830 & 4469 & 4622 & 4586 & 751 & 885 & 682 & 886 \\
\hline 4 & 1120 & 1630 & 3853 & 4292 & 4611 & 4349 & 824 & 850 & 748 & 838 \\
\hline 000004 & 1124 & 1673 & 3668 & 4275 & 4418 & 4381 & 835 & 874 & 763 & 837 \\
\hline 444000 & 1033 & 1642 & 3757 & 4320 & 4523 & 4388 & 735 & 832 & 662 & 833 \\
\hline 444003 & 1168 & 1658 & 3850 & 4348 & 4581 & 4430 & 879 & 865 & 812 & 844 \\
\hline \# of obs. & \multicolumn{2}{|c|}{69951} & \multicolumn{2}{|c|}{8997} & \multicolumn{2}{|c|}{8665} & \multicolumn{2}{|c|}{4964} & \multicolumn{2}{|c|}{7423} \\
\hline
\end{tabular}

Note: $\quad$ The first element of each sequence refers to period 3(1). mean: Mean in subsample; SD: Standard deviation in subsample. 
Table A.1b: Mean and standard deviation of potential earnings in 9(4) in selected subsamples

\begin{tabular}{|c|c|c|c|c|c|c|c|c|c|c|}
\hline \multirow[t]{3}{*}{ Sequence } & \multicolumn{10}{|c|}{ Subsample (treatment state in period 3(1)) } \\
\hline & \multicolumn{2}{|c|}{0} & \multicolumn{2}{|c|}{1} & \multicolumn{2}{|c|}{2} & \multicolumn{2}{|c|}{3} & \multicolumn{2}{|c|}{4} \\
\hline & mean & SD & mean & SD & mean & SD & mean & SD & mean & SD \\
\hline 000000 & 990 & 1638 & 3696 & 4109 & 4487 & 4173 & 670 & 863 & 587 & 850 \\
\hline 01 & 1275 & 1707 & 3975 & 4169 & 4757 & 4219 & 938 & 981 & 848 & 961 \\
\hline 001 & 1290 & 1832 & 4065 & 4382 & 4837 & 4486 & 951 & 1062 & 851 & 1043 \\
\hline 0001 & 1234 & 1819 & 3982 & 4397 & 4779 & 4512 & 896 & 1021 & 800 & 1011 \\
\hline 000001 & 1242 & 1785 & 3923 & 4263 & 4720 & 4391 & 923 & 1019 & 814 & 977 \\
\hline 1 & 1337 & 1690 & 4022 & 4087 & 4786 & 4131 & 1007 & 967 & 916 & 955 \\
\hline 11 & 1348 & 1707 & 4054 & 4133 & 4821 & 4175 & 1015 & 975 & 924 & 963 \\
\hline 111 & 1362 & 1738 & 4109 & 4216 & 4883 & 4251 & 1026 & 993 & 933 & 978 \\
\hline 1111 & 1398 & 1775 & 4192 & 4314 & 4968 & 4339 & 1057 & 1022 & 963 & 1009 \\
\hline 10 & 297 & 1635 & 3896 & 3940 & 4646 & 3996 & 980 & 938 & 886 & 929 \\
\hline 110 & 1331 & 1680 & 3989 & 4063 & 4752 & 4113 & 1003 & 960 & 912 & 952 \\
\hline 1110 & 1351 & 1730 & 4083 & 4194 & 4855 & 4233 & 1016 & 987 & 923 & 971 \\
\hline 11110 & 1405 & 1771 & 4186 & 4300 & 4959 & 4328 & 1065 & 1021 & 971 & 1008 \\
\hline 111000 & 1275 & 1707 & 3959 & 4321 & 4762 & 4367 & 816 & 954 & 729 & 940 \\
\hline 111002 & 1866 & 1856 & 4372 & 4240 & 5037 & 4355 & 1173 & 1074 & 1500 & 1215 \\
\hline 2 & 1991 & 1025 & 4502 & 4258 & 5151 & 4348 & 1661 & 1181 & 1456 & 1173 \\
\hline 22 & 1990 & 1843 & 4511 & 4274 & 5162 & 4363 & 2449 & 2664 & 1636 & 1222 \\
\hline 222 & 1889 & 1853 & 4528 & 4307 & 5182 & 4392 & 1656 & 1186 & 1633 & 1225 \\
\hline 2222 & 1977 & 1878 & 4567 & 4388 & 5232 & 4469 & 1639 & 1190 & 1613 & 1232 \\
\hline 222000 & 1791 & 1751 & 4274 & 4147 & 4934 & 4242 & 1462 & 1073 & 1444 & 1118 \\
\hline 222001 & 2060 & 1922 & 4559 & 4323 & 5233 & 4438 & 1734 & 1250 & 1686 & 1259 \\
\hline 3 & 1025 & 1712 & 3705 & 4341 & 4467 & 4436 & 697 & 902 & 617 & 888 \\
\hline 33 & 1026 & 1717 & 3713 & 4355 & 4477 & 4450 & 1520 & 2653 & 617 & 890 \\
\hline 333 & 1034 & 1734 & 3743 & 4399 & 4508 & 4492 & 1532 & 2677 & 622 & 899 \\
\hline 0003 & 1002 & 1752 & 3685 & 4446 & 4479 & 4589 & 1499 & 2706 & 606 & 931 \\
\hline 00033 & 1003 & 1759 & 3696 & 4466 & 4491 & 4611 & 755 & 878 & 607 & 934 \\
\hline 000333 & 1004 & 1774 & 3716 & 4508 & 4514 & 4653 & 751 & 885 & 606 & 939 \\
\hline 4 & 1116 & 1715 & 3913 & 4352 & 4695 & 4396 & 788 & 912 & 704 & 899 \\
\hline 000004 & 1041 & 1743 & 4502 & 4258 & 4464 & 4461 & 742 & 958 & 886 & 926 \\
\hline 444000 & 1056 & 1716 & 3830 & 4344 & 4620 & 4405 & 724 & 897 & 649 & 886 \\
\hline 444003 & 1047 & 1734 & 3685 & 4394 & 4413 & 4474 & 744 & 922 & 669 & 917 \\
\hline \# of obs. & \multicolumn{2}{|c|}{69951} & \multicolumn{2}{|c|}{8997} & \multicolumn{2}{|c|}{8665} & \multicolumn{2}{|c|}{4964} & \multicolumn{2}{|c|}{7423} \\
\hline
\end{tabular}

Note: $\quad$ The first element of each sequence refers to period 3(1). mean: Mean in subsample; SD: Standard deviation in subsample. 
Table A.2a: Percentage employed in 7(4) in selected subsamples in \%

\begin{tabular}{|c|c|c|c|c|c|}
\hline \multirow[t]{2}{*}{ Sequence } & \multicolumn{5}{|c|}{ Subsample (treatment state in period 3(1)) } \\
\hline & 0 & 1 & 2 & 3 & 4 \\
\hline 000000 & 58 & 71 & 74 & 56 & 50 \\
\hline 01 & 96 & 97 & 97 & 95 & 95 \\
\hline 001 & 95 & 96 & 95 & 95 & 95 \\
\hline 0001 & 92 & 94 & 96 & 91 & 91 \\
\hline 000001 & 91 & 93 & 94 & 89 & 89 \\
\hline 1 & 97 & 98 & 98 & 97 & 97 \\
\hline 11 & 97 & 98 & 98 & 97 & 97 \\
\hline 111 & 97 & 98 & 98 & 97 & 97 \\
\hline 1111 & 97 & 98 & 98 & 97 & 97 \\
\hline 10 & 97 & 98 & 98 & 97 & 97 \\
\hline 110 & 97 & 98 & 98 & 97 & 97 \\
\hline 1110 & 97 & 98 & 98 & 97 & 97 \\
\hline 11110 & 97 & 98 & 98 & 97 & 97 \\
\hline 111000 & 96 & 98 & 98 & 95 & 95 \\
\hline 111002 & 90 & 90 & 89 & 90 & 91 \\
\hline 2 & 81 & 82 & 82 & 82 & 80 \\
\hline 22 & 81 & 82 & 82 & 81 & 80 \\
\hline 222 & 81 & 83 & 82 & 82 & 80 \\
\hline 2222 & 80 & 82 & 81 & 81 & 79 \\
\hline 222000 & 79 & 81 & 80 & 80 & 78 \\
\hline 222001 & 96 & 97 & 96 & 97 & 96 \\
\hline 3 & 71 & 81 & 82 & 67 & 65 \\
\hline 33 & 70 & 80 & 82 & 72 & 65 \\
\hline 333 & 71 & 80 & 82 & 72 & 65 \\
\hline 0003 & 76 & 83 & 84 & 77 & 73 \\
\hline 00033 & 76 & 83 & 84 & 74 & 73 \\
\hline 000333 & 76 & 83 & 84 & 74 & 73 \\
\hline 4 & 75 & 85 & 86 & 78 & 75 \\
\hline 000004 & 81 & 85 & 86 & 80 & 78 \\
\hline 444000 & 76 & 82 & 85 & 68 & 72 \\
\hline 444003 & 90 & 92 & 92 & 65 & 89 \\
\hline \# of obs. & 69951 & 8997 & 8665 & 4964 & 7423 \\
\hline
\end{tabular}


Table A.2b: Percentage employed in 9(4) in selected subsamples in \%

\begin{tabular}{|c|c|c|c|c|c|}
\hline \multirow[t]{2}{*}{ Sequence } & \multicolumn{5}{|c|}{ Subsample (treatment state in period 3(1)) } \\
\hline & 0 & 1 & 2 & 3 & 4 \\
\hline \multicolumn{6}{|c|}{ Employment in 9(4) in \%-points } \\
\hline 000000 & 58 & 72 & 75 & 56 & 50 \\
\hline 01 & 78 & 85 & 87 & 76 & 74 \\
\hline 001 & 79 & 85 & 86 & 77 & 76 \\
\hline 0001 & 78 & 85 & 86 & 77 & 75 \\
\hline 000001 & 84 & 89 & 90 & 83 & 81 \\
\hline 1 & 80 & 87 & 89 & 81 & 78 \\
\hline 11 & 81 & 87 & 89 & 81 & 78 \\
\hline 111 & 82 & 87 & 89 & 82 & 79 \\
\hline 1111 & 82 & 87 & 89 & 82 & 79 \\
\hline 10 & 80 & 86 & 88 & 80 & 76 \\
\hline 110 & 81 & 87 & 87 & 81 & 78 \\
\hline 1110 & 81 & 87 & 89 & 82 & 79 \\
\hline 11110 & 82 & 88 & 90 & 83 & 80 \\
\hline 111000 & 77 & 85 & 87 & 77 & 74 \\
\hline 111002 & 88 & 88 & 89 & 89 & 87 \\
\hline 2 & 86 & 84 & 83 & 87 & 86 \\
\hline 22 & 86 & 84 & 83 & 85 & 86 \\
\hline 222 & 86 & 84 & 83 & 87 & 86 \\
\hline 2222 & 86 & 84 & 83 & 86 & 85 \\
\hline 222000 & 85 & 83 & 82 & 86 & 84 \\
\hline 222001 & 95 & 94 & 94 & 94 & 94 \\
\hline 3 & 58 & 70 & 72 & 55 & 50 \\
\hline 33 & 58 & 70 & 72 & 59 & 50 \\
\hline 333 & 59 & 70 & 72 & 59 & 50 \\
\hline 0003 & 56 & 69 & 72 & 58 & 49 \\
\hline 00033 & 56 & 69 & 72 & 75 & 49 \\
\hline 000333 & 56 & 69 & 72 & 75 & 49 \\
\hline 4 & 71 & 80 & 82 & 70 & 65 \\
\hline 000004 & 69 & 78 & 80 & 67 & 64 \\
\hline 444000 & 69 & 79 & 81 & 68 & 63 \\
\hline 444003 & 66 & 75 & 77 & 65 & 61 \\
\hline \# of obs. & 69951 & 8997 & 8665 & 4964 & 7423 \\
\hline
\end{tabular}

